\title{
On the representation of immersion and condensation freezing in cloud models using different nucleation schemes
}

\author{
B. Ervens ${ }^{1,2}$ and G. Feingold ${ }^{2}$ \\ ${ }^{1}$ Cooperative Institute for Research in Environmental Sciences, University of Colorado, Boulder, Colorado, USA \\ ${ }^{2}$ Chemical Sciences Division, NOAA Earth System Research Laboratory, Boulder, Colorado, USA
}

Correspondence to: B. Ervens (barbara.ervens@noaa.gov)

Received: 22 February 2012 - Published in Atmos. Chem. Phys. Discuss.: 9 March 2012

Revised: 12 June 2012 - Accepted: 13 June 2012 - Published: 6 July 2012

\begin{abstract}
Ice nucleation in clouds is often observed at temperatures $>235 \mathrm{~K}$, pointing to heterogeneous freezing as a predominant mechanism. Many models deterministically predict the number concentration of ice particles as a function of temperature and/or supersaturation. Several laboratory experiments, at constant temperature and/or supersaturation, report heterogeneous freezing as a stochastic, timedependent process that follows classical nucleation theory; this might appear to contradict deterministic models that predict singular freezing behavior.

We explore the extent to which the choice of nucleation scheme (deterministic/stochastic, single/multiple contact angles $\theta$ ) affects the prediction of the fraction of frozen ice nuclei (IN) and cloud evolution for a predetermined maximum IN concentration. A box model with constant temperature and supersaturation is used to mimic published laboratory experiments of immersion freezing of monodisperse $(800 \mathrm{~nm})$ kaolinite particles $(\sim 243 \mathrm{~K})$, and the fitness of different nucleation schemes. Sensitivity studies show that agreement of all five schemes is restricted to the narrow parameter range (time, temperature, IN diameter) in the original laboratory studies, and that model results diverge for a wider range of conditions.

The schemes are implemented in an adiabatic parcel model that includes feedbacks of the formation and growth of drops and ice particles on supersaturation during ascent. Model results for the monodisperse IN population $(800 \mathrm{~nm})$ show that these feedbacks limit ice nucleation events, often leading to smaller differences in number concentration of ice particles and ice water content (IWC) between stochastic and deterministic approaches than expected from the box model studies. However, because the different parameterizations of $\theta$
\end{abstract}

distributions and time-dependencies are highly sensitive to IN size, simulations using polydisperse IN result in great differences in predicted ice number concentrations and IWC between the different schemes. The differences in IWC are mostly due to the different temperatures of the onset of freezing in the nucleation schemes that affect the temporal evolution of the ice number concentration. The growth rates of ice particles are not affected by the choice of the nucleation scheme, which leads to very similar particle sizes. Finally, since the choice of nucleation scheme determines the temperature range over which ice nucleation occurs, at habit-prone temperatures $(\sim 253 \mathrm{~K})$, there is the potential for variability in the initial inherent growth ratio of ice particles, which can cause amplification or reduction in differences in predicted IWC.

\section{Introduction}

The interactions of aerosol particles and clouds represent the largest uncertainty in current estimates of radiative forcing (Solomon et al., 2007). The uncertainty is particularly acute in mixed-phase clouds, which play an important role in modulating climate. For example, mixed-phase clouds are often observed in the Arctic and significantly influence radiation and energy budgets (e.g., Curry, 1995; Fridlind et al., 2007; Morrison et al., 2012). Efficient ice formation at temperatures $235 \mathrm{~K}<T<273 \mathrm{~K}$ suggests the existence of ice nuclei (IN) that heterogeneously nucleate ice. Observations of mixed-phase clouds have shown that ice forms over relatively long time scales and in the presence of a liquid phase prior to ice formation (e.g., Hobbs and Rangno, 1985; Crosier et 
al., 2011; Crawford et al., 2012). These observations might imply that ice nucleation occurs by freezing of droplets (immersion freezing) (de Boer et al., 2010; Lance et al., 2011).

To avoid undue complexity in the representation of poorly constrained freezing processes, models often apply parameterizations that are based on observed relationships between the number concentration of ice particles $\left(N_{\text {ice }}\right)$ and $T$ and/or ambient supersaturation with respect to ice $\left(S_{\text {ice }}\right)$ (e.g., Fletcher, 1969; Meyers et al., 1992; Cotton and Field, 2002; Morrison et al., 2008; Phillips et al., 2008; Eidhammer et al., 2009; de Boer et al., 2010; DeMott et al., 2010). Such empirical expressions have been developed based on observed freezing events and reflect the instantaneous conditions of the ice phase in the corresponding temperature and/or $S_{\text {ice }}$ range. They imply singular, time-independent freezing on active sites on the surface of IN, at specific temperatures during cloud evolution (Langham and Mason, 1958). Laboratory experiments are often performed in a way that only the onset of freezing is recorded (e.g., Crawford et al., 2011; Wang and Knopf, 2011; Wheeler and Bertram, 2012). In such experiments, the number concentration of frozen particles is reported as an integrated number over the investigated temperature and/or supersaturation range (e.g., Vali, 2008; Niedermeier et al., 2010; Niemand et al., 2012).

Singular freezing behavior is in contradiction to many laboratory measurements that report continuous ice formation during experiments at constant $T$ and/or $S_{\text {ice }}$ or as a function of cooling rate (Diehl and Wurzler, 2004; Zobrist et al., 2007; Popovicheva et al., 2008; Kulkarni and Dobbie, 2010; Murray et al., 2010; Niedermeier et al., 2010; Welti et al., 2012). Parameterizations of the number of frozen particles as a function of cooling rates have been developed in order to describe the freezing behavior of biological material or other solutes immersed in water drops (Bigg, 1953; Vonnegut and Baldwin, 1984; Diehl et al., 2002). Such experimental results are in agreement with classical nucleation theory (CNT) that describes ice nucleation as a stochastic, time-dependent process (Fukuta and Schaller, 1982; Khvorostyanov and Curry, 2000; Shaw et al., 2005; Curry and Khvorostyanov, 2012).

Several studies attempt to reconcile these discrepancies between the singular approaches that imply that active sites on IN are unambiguously associated with their freezing conditions and CNT-based stochastic approaches. While the two descriptions of heterogeneous freezing appear to be fundamentally different, stochastic freezing might exhibit no (or very little) time dependence if freezing occurs rapidly (Vali, 1971, 2008). The interpretation of experimental data has shown that neither of the approaches can fully explain freezing behavior of water droplets or dust particles (Vali and Stansbury, 1966; Gorbunov et al., 2001; Marcolli et al., 2007; Broadley et al., 2012). A modified singular hypothesis was developed that accounts for a random distribution of active sites which leads to a distribution of the onset of freezing temperatures among droplet samples (Vali and Stansbury, 1966; Vali, 2008). A recently developed theoret- ical framework shows how the deterministic and stochastic descriptions converge as the number of randomly distributed nucleation sites increases (Niedermeier et al., 2011) or if the time scales over which freezing occurs are sufficiently short and thus no dependence on freezing rate can be detected (Broadley et al., 2012). In practice, the two approaches might also not be clearly distinguishable because of the temporal and temperature-dependent aspects of ice formation (stochasticity) (Vali and Stansbury, 1966; Vali, 1994; Field et al., 2011).

CNT for condensation and immersion freezing includes physicochemical parameters that characterize particle properties that affect water uptake by haze particles, droplet activation prior to freezing, and ice nucleation on insoluble cores within the deliquesced particles or drops (Khvorostyanov and Curry, 2004). In many studies, an effective contact angle $\theta$ has been derived from experimentally-determined nucleation rates $J$ for different IN, assuming that $\theta$ is the only unknown parameter in the CNT (e.g., Archuleta et al., 2005; Chen et al., 2008; Wang and Knopf, 2011). $\theta$ is defined as an effective macroscopic quantity that parameterizes the interactions of ice with the IN surface. While the compatibility of the ice crystal with the solid IN surface cannot be directly measured, $\theta$ provides a convenient way to describe these interactions. Recent laboratory studies suggest that a single $\theta$ for one type of IN of identical bulk composition is inadequate to characterize the freezing behavior of individual particles and/or aerosol populations (Marcolli et al., 2007; Welti et al., 2009; Lüönd et al., 2010; Niedermeier et al., 2010; Murray et al., 2011; Broadley et al., 2012; Wheeler and Bertram, 2012).

Time-dependent freezing processes imply that at a given $T$ not all particles are frozen. Thus, experimental or model studies often distinguish between the number concentration of potential ice nuclei $\left(N_{\mathrm{IN}}\right)$ and the concentration of ice crystals at a given time $\left(N_{\text {ice }}\right)$ (e.g., Eidhammer et al., 2009; Kulkarni and Dobbie, 2010). Fits to the observed temperature-dependence of the frozen fraction $F_{\mathrm{fr}}$ of the IN number concentration $N_{\mathrm{IN}}\left(F_{\mathrm{fr}}=N_{\text {ice }} / N_{\mathrm{IN}}\right)$ in these experiments provide parameters for different $\theta$ distributions and deterministic expressions that all reproduce the observed $F_{\mathrm{fr}}$ over the range of experimental conditions. A recent model study shows that cloud properties might differ greatly if different parameter sets are applied (Kulkarni et al., 2012). The authors ascribed these differences to the variation in temperature and supersaturation of the onset of freezing due to the width of the $\theta$ distribution.

The goal of this study is to analyze in detail the microphysical processes and their feedbacks on cloud properties $\left(N_{\text {ice }}\right.$, ice water content (IWC), ice distributions) resulting from different nucleation schemes. We do so by using a variety of nucleation schemes, all of which are able to mimic laboratory nucleation events over a limited period of time. Using a series of models of increasing complexity, we shed light on the similarities and differences in these nucleation schemes for a variety of conditions near the temperature range for which 

a) $1 \theta$
b) ӨPDF
c) Soccer (int)
d) Soccer (ext)
e) Deterministic
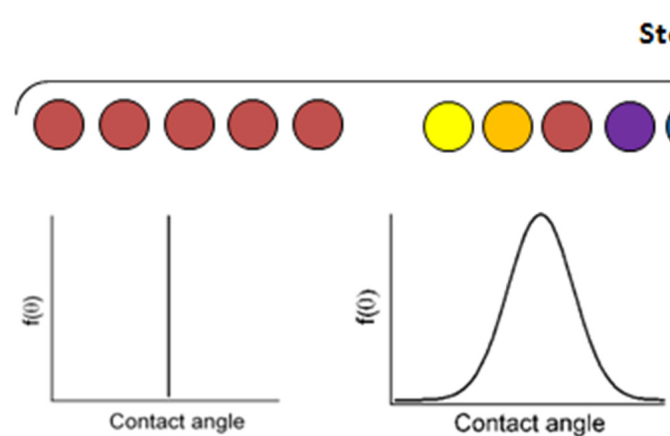

Stochastic

人

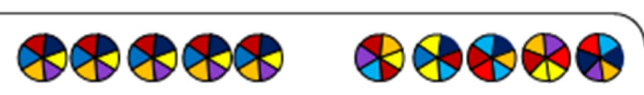

$\begin{aligned} F_{\text {fr }} & =N_{\text {ice }} / N_{\text {IN }} \\ & =f\left(T, D_{\text {IN }}\right)\end{aligned}$

Fig. 1. Nucleation schemes that have been developed to describe freezing of kaolinite (Lüönd et al., 2010). Parameters to describe the $\theta$ distributions and temperature dependence of $F_{\mathrm{fr}}$ are summarized in Table 1.

the schemes were derived, and their potential consequences for cloud evolution. We focus on the evolution of the frozen fraction of a predetermined IN concentration, chosen such that that the coexistence of ice and liquid phases is predicted.

\section{Model description}

\subsection{Ice nucleation schemes}

A number of stochastic and deterministic nucleation schemes have been put forth to explain observed freezing behavior in the laboratory (Lüönd et al., 2010; Niedermeier et al., 2010, 2011; Alpert et al., 2011; Niemand et al., 2012) and field (Fletcher, 1969; Meyers et al., 1992; DeMott et al., 2010). Their differences are explained in the following.

\subsection{1 $1 \theta$ scheme}

CNT implies that the surface of particles of identical bulk composition can be characterized by a single $\theta$ as the dominant physicochemical property that determines their IN ability $(1 \theta$; Fig. 1a). The nucleation rate $J$ is a function of the IN diameter $\left(D_{\text {IN }}\right)$, the activation energy at the solution-ice interface $\Delta F_{\text {act }}$, and the critical energy of ice germ formation $\Delta F_{\mathrm{cr}}$ (Khvorostyanov and Curry, 2004)

$J=\frac{k T}{h} \frac{\pi}{6} \times 10^{19} \mathrm{~m}^{-2} D_{\mathrm{IN}}^{2} \exp \left[-\frac{\Delta F_{\mathrm{act}}-\Delta F_{\mathrm{cr}}}{k T}\right]$

$k \quad$ Boltzmann constant $\left[1.3806504 \times 10^{-23} \mathrm{~J} \mathrm{~K}^{-1}\right]$

$h$ Planck's constant $\left[6.626068 \times 10^{-34} \mathrm{~m}^{2} \mathrm{~kg} \mathrm{~s}^{-1}\right]$

$T$ temperature [K]

with a parameterized expression for $\Delta F_{\text {act }}$ (Jeffery and Austin, 1997; Khvorostyanov and Curry, 2005)

$$
\Delta F_{\text {act }}=0.694 \times 10^{-12} \times\left(1+0.0027 \times\left(T_{\mathrm{C}}\left[^{\circ} \mathrm{C}\right]+30\right)\right)[J]
$$

The formation energy of an ice germ is a function of the cosine of the contact angle $(\cos (\theta)=m)$

$$
\Delta F_{\mathrm{cr}}=4 / 3 \pi \sigma_{\mathrm{i}, \mathrm{s}} \times r_{\mathrm{germ}}^{2} \times f(m, x)[J]
$$

$\sigma_{\mathrm{i}, \mathrm{s}} \quad$ surface tension at the ice/solution interface $\left[\mathrm{N} \mathrm{m}^{-1}\right]$

$r_{\text {germ }}$ ice germ radius [m]

$f(m, x) \quad$ geometric factor

$x \quad r_{\text {germ }} /\left(D_{\mathrm{IN}} / 2\right)$

The germ radius to initiate nucleation is a function of the bulk properties of the aerosol particle and is calculated as

$$
r_{\text {germ }}=\frac{2 \sigma_{\text {is }}}{\rho_{\text {ice }} L_{\mathrm{m}}^{\mathrm{ef}} \ln \left(\frac{273.15}{T}\right)+\frac{R T \rho_{\text {ice }}}{M_{\mathrm{w}}} H_{c}-\frac{2 \sigma_{\mathrm{sa}}}{r_{d}}}
$$

$R \quad$ universal gas constant $\left[\mathrm{J} \mathrm{K}^{-1} \mathrm{~mol}^{-1}\right]$

$\rho_{\text {ice }}$ density of ice $\left[\mathrm{kg} \mathrm{m}^{-3}\right]$

$L_{\mathrm{m}}^{\text {ef }} \quad$ effective average latent heat of melting $\left[\mathrm{J} \mathrm{kg}^{-1}\right]$

$M_{\mathrm{w}} \quad$ molecular weight of water $\left[\mathrm{kg} \mathrm{mol}^{-1}\right]$

$\sigma_{\mathrm{sa}}$ surface tension at the solution/air interface $\left[\mathrm{N} \mathrm{m}^{-1}\right]$

$r_{\mathrm{d}} \quad$ droplet radius [m]

and

$H_{c}=\frac{2 \sigma_{\mathrm{sa}} M_{\mathrm{w}}}{\rho_{\mathrm{w}} R T r_{\mathrm{d}}}-\frac{\nu \Phi\left(1-\varepsilon_{\text {insol }}\right) M_{\mathrm{w}} \rho_{\mathrm{s}} r_{s}^{3}}{M_{\mathrm{s}} \rho_{\mathrm{w}}\left(r_{s}^{3}-r_{\mathrm{d}}^{3}\right)}$

$\rho_{\mathrm{w}} \quad$ density of water $\left[\mathrm{kg} \mathrm{mol}^{-1}\right]$

$\nu \phi \quad$ van't Hoff factor

$\varepsilon_{\text {insol }}$ insoluble mass fraction

$\rho_{\mathrm{S}} \quad$ density of solute $\left[\mathrm{kg} \mathrm{mol}^{-1}\right]$

$r_{s} \quad$ radius of dry particle $[\mathrm{m}]$

$M_{\text {s }} \quad$ molecular weight of solute $\left[\mathrm{kg} \mathrm{mol}^{-1}\right]$

Since deliquesced particles are near their equilibrium state, except perhaps for the larger ones, and the equilibrium supersaturation $S_{\mathrm{w}, \text { eq }}$ above a particles does not differ significantly from the ambient supersaturation $S_{\mathrm{w}}$, it can be 
assumed that

$\ln S_{\mathrm{w}} \sim \ln S_{\mathrm{w}, \mathrm{eq}}=H_{c}$

and Eq. (4) can be approximated by

$$
r_{\text {germ }}=\frac{2 \sigma_{\text {is }}}{\rho_{\text {ice }} L_{\mathrm{m}}^{\mathrm{ef}} \ln \left(\frac{273.15}{T} S_{\mathrm{w}}\right)^{\left[R T /\left(M_{\mathrm{w}} L_{\mathrm{m}}^{\mathrm{ef}}\right)\right]}-\frac{2 \sigma_{\mathrm{sa}}}{r_{\mathrm{d}}}} .
$$

In the presence of water, i.e. if $S_{\mathrm{w}} \geq 1$, the ambient supersaturation $S_{\mathrm{w}}$ deviates substantially from $S_{\mathrm{w}, \text { eq }}$ and Eq. (7) is not valid. For such situations, the explicit expression in Eq. (4) is used.

Thus, the probability $P$ that a particle freezes within a given time $t$ is influenced by $\theta$ in the exponential term $\Delta F_{\text {cr }}$ in Eq. (1)

$$
P_{1 \theta}=1-\exp (-J t)
$$

\subsection{2 $\theta$ PDF scheme}

Since the freezing ability of IN is a function of surface properties ( $\sigma_{\mathrm{i}, \mathrm{s}}$ and $\theta$, in Eq. 3 ), identical bulk composition of IN might not translate to the same freezing behavior of particles within an IN population. It has been suggested that IN populations are externally mixed with respect to their surface properties (Fig. 1b) since observed differences in freezing behavior of equally-sized particles cannot be fully explained by stochastic processes of identical surfaces (Marcolli et al., 2007). The freezing probability of a particle within such a population of $N$ particles is a weighted average of the freezing probabilities of all individual particles

$P_{\theta \mathrm{PDF}}=\frac{1}{N} \sum_{i}^{N} P_{i}$

Such an external mixture of particles implies that particles with the smallest $\theta$ are the most likely to freeze. Data from immersion and deposition freezing experiments have shown that the probability density function (PDF) of $\theta$ over the particle population can be described by lognormal distributions (Lüönd et al., 2010; Kulkarni et al., 2012; Wheeler and Bertram, 2012).

\subsubsection{Internally-mixed soccer ball scheme (soccer (int))}

While both the $1 \theta$ and the $\theta$ PDF scheme describe the surface of each particle with a single $\theta$, images of IN show surfaces that are not smooth and uniform but exhibit numerous possible nucleating sites (cracks, imperfections, crystal structure, etc.; e.g., Kumai, 1951; Bryant et al., 1959; Fukuta, 1966; Kulkarni and Dobbie, 2010). This diversity suggests that each IN might exhibit numerous nucleation sites which comprise a distribution of contact angles.

Niedermeier et al. (2011) introduced the term "soccer balls" for particles with multiple nucleation sites, to reflect the patches that make up the surface of a soccer ball. The simplest soccer ball scheme assumes that all particles within a population have the same distribution of contact angles throughout their surfaces; thus, particles are identical and appear to be internally mixed ("int") with respect to the surface characteristics that determine ice nucleation (Fig. 1c). The overall freezing probability of a particle with $n$ nucleation sites is the product of the individual freezing probabilities of each nucleation site $j$, weighted by the fraction $S_{j}$ a single nucleation site covers on the total particle surface

$P_{\text {socint }}=1-\prod_{j}^{n}\left[\exp \left(-J_{j} S_{j} t\right)\right]$

As $J$ depends exponentially on $\Delta F_{\text {cr }}$, which includes $\theta$ in the geometric factor $f(m, x)$ (Eq. 3), the relative impact of a nucleation site $j$ with a small $\theta_{j}$ on $J_{j}$ in the exponential term in Eq. (10) will tend to be greater than the weighting factor $S_{j}$. Thus, a single nucleation site can dominate the overall freezing probability $P_{\text {socint }}$ if $\theta_{j}$ (and/or $S_{j}$ ) are sufficiently low.

\subsubsection{Externally-mixed soccer ball scheme (soccer (ext))}

Both the $\theta$ PDF and the soccer (int) scheme are idealized representations of $\theta$ distributions associated with IN populations since they assume particles with identical surface properties. A more realistic description represents the combination of these two schemes as it is likely that statistical $\theta$ distributions extend over the total surface area of an aerosol population rather than being confined to a single particle. Thus, particles are externally mixed ("ext") soccer balls with respect to their $\theta$ distributions (Fig. 1d). Such distributions have been referred to as active site distributions (Marcolli et al., 2007; Welti et al., 2012) or probability dispersion functions (Barahona, 2012).

The freezing probability of a population of $N$ different particles that each have $n$ nucleation sites can be described by a combination of Eqs. (9) and (10). Lüönd et al. (2010) have shown that the surface density of nucleation sites can be fit to an exponential expression with very few relatively low contact angles and a nearly uniform $\theta$ distribution towards higher values (bottom panel of Fig. 1d). A surface-density dependent $\theta$ distribution over the surface of an IN population could explain higher IN efficiency for larger particles as they likely have a greater number of nucleation sites and a statistically higher probability of freezing, exceeding the increase in $P$ that is predicted due to IN size based on CNT (Eq. 1) (Welti et al., 2009). Niedermeier et al. (2011) have shown that the increase in $n$ on a single particle can explain the transition from stochastic to apparently singular freezing behavior since statistically the abundance of efficient nucleation sites increases. These findings are in qualitative agreement with those by Fletcher (1958) who showed a strong size-dependence of freezing ability of particles smaller than $\sim 100 \mathrm{~nm}$ whereas this dependence is significantly reduced at larger sizes. 


\subsubsection{Deterministic scheme}

Laboratory studies often report the number of frozen particles integrated over a $T$ range as a function of the density of active sites (e.g., Vali, 2008; Connolly et al., 2009; Niedermeier et al., 2010; Alpert et al., 2011). Such a cumulative activation spectrum has been described as (e.g., Vali, 1971, 1994)

$k(T)=\frac{1}{V \cdot N(T)} \frac{\mathrm{d} N}{\mathrm{~d} T}$

$V \quad$ volume of unfrozen particles

$N(T) \quad$ number of unfrozen particles

Such functions imply that particle surfaces are characterized by specific sites that unambiguously freeze at a certain $T$. Lüönd et al. (2010) showed that the freezing behavior of kaolinite particles immersed in droplets can be described by

$$
F_{\mathrm{fr}}=1-\exp \left[-S_{\mathrm{IN}} A_{1}\left(T+A_{2}\right)^{2}\right]
$$

below a temperature threshold $-A_{2}\left[{ }^{\circ} \mathrm{C}\right]$, and $F_{\mathrm{fr}}=0$ at higher temperatures. Since this relationship was derived for conditions where immersion freezing occurs $\left(S_{\mathrm{W}}>1\right)$ it might not be applicable to condensation freezing $\left(S_{\mathrm{W}}<1\right)$.

A dependence of the number of frozen particles on $T$ has been observed in the atmosphere. Based on such observations, empirical expressions have been developed that deterministically predict $N_{\text {ice }}$ (Fletcher, 1969; Cotton et al., 1986; Meyers et al., 1992). Such parameterizations often do not include any constraint on the total $N_{\text {ice }}$, i.e., they are not limited by the number of potential IN that exist in an aerosol population as opposed to laboratory studies where this number is constrained by the sample size in the ice chamber. The need for such constraints on $N_{\text {IN }}$ has been discussed in detail in recent studies (e.g., Phillips et al., 2008; Eidhammer et al., 2009).

\subsection{Description of the box model}

Lüönd et al. (2010) performed experiments of immersion freezing of kaolinite particles in an ice chamber where particles had a residence time of $\sim 14 \mathrm{~s}$ at constant temperature and supersaturation. They presented $F_{\mathrm{fr}}$ as a function of $T$ for experiments in a range of $237.5 \mathrm{~K}<T<241.0 \mathrm{~K}$. In order to parameterize the observed freezing behavior, they fitted different nucleation schemes (Fig. 1a, b, c, e) to the experimental results and demonstrated that with the derived fit parameters all schemes predict $F_{\text {fr }}$ very similar to each other and to the experimental data.

In order to anchor our simulations in the realism of laboratory experiments, we perform box model studies that closely mimic the simulations by Lüönd et al. (2010) using their different nucleation schemes. For the externally mixed schemes $(\theta$ PDF and soccer(ext)), we assume 20 different particles for all model simulations. The distribution of randomly-selected nucleation sites on particle surfaces is assumed to include 80 (soccer(int)) or 50 (soccer(ext) different contact angles on each particle surface. These selections represent the distributions in the bottom panel of Fig. 1 reasonably well, and are summarized in Table 1.

The box model describes in detail the activation of monodisperse aerosol particles to droplets using Köhler theory over a range of relative humidity with respect to water, $99 \%<\mathrm{RH}_{\mathrm{W}}<100.2 \%$. After an initialization period (1 s), $\mathrm{RH}_{\mathrm{w}}$ is kept constant at supersaturated conditions (supersaturation with respect to water, $S_{\mathrm{W}}=0.2 \%$ ) in order to prevent droplets from evaporating and to allow formation of ice particles through immersion freezing. Simulations are performed at 12 temperatures, constant over the simulation time, in the same range as the laboratory experiments by Lüönd et al. (2010). The temperature together with the constant $S_{\mathrm{W}}$ determines $S_{\text {ice }}$ in each simulation.

Limitations of the experimental setups do not allow continuing laboratory experiments for times much beyond the initial nucleation events owing to the rapid decline of $S_{\text {ice }}$ by efficient water vapor deposition on the newly formed ice particles (Lüönd et al., 2010; Wheeler and Bertram, 2012). However, the box model allows us to explore numerically the temporal evolution of predicted $F_{\text {fr }}$ beyond the initial freezing events using the various nucleation schemes described in Sect. 2.1.

\subsection{Description of the adiabatic parcel model}

In contrast to the box model simulations where temperature, $S_{\mathrm{w}}$, and $S_{\text {ice }}$ are constant, the cloud parcel model simulates the dynamical feedbacks on the supersaturation field as a result of the source due to the cooling rate $(\propto$ constant updraft velocity $w$ ), and sinks by the water vapor condensation onto growing aerosol particles, droplets and deposition on ice particles:

$$
\frac{\mathrm{d} S_{\text {ice }}}{\mathrm{d} t} \propto \frac{\mathrm{d} S_{\mathrm{W}}}{\mathrm{d} t}=\underbrace{C \cdot w}_{\text {Cooling }}-\underbrace{\varphi_{1} \frac{\mathrm{dLWC}}{\mathrm{d} t}}_{\text {Condensation }}-\underbrace{\varphi_{2} \frac{\mathrm{dIWC}}{\mathrm{d} t}}_{\text {Deposition }},
$$

where $C, \varphi_{1}, \varphi_{2}$ are well-known functions of temperature, pressure and ambient supersaturation, and LWC and IWC represent the liquid (i.e., water on droplets and aerosol particles) and ice water contents $\left[\mathrm{g} \mathrm{kg}^{-1}\right]$, respectively. Timedependent differential equations describing the change in state variables and the growth of haze particles, droplets and ice particles are solved simultaneously. Other than at the initial conditions, haze particles are not assumed to be at their equilibrium sizes.

Simulations are performed for constant $w$ and consider a single ascent of an air parcel for $300 \mathrm{~m}$. Thus, particles are always in a deliquesced state as they are exposed to conditions where $0.8<S_{\mathrm{w}}<\sim 1$ with the lower limit only achieved in situations where ice growth represents an efficient sink for water vapor (Bergeron-Findeisen process). 
Table 1. Parameters to describe contact angle $(\theta)$ distributions for the different nucleation schemes as used in the box and parcel models. Note for both the box and the parcel models the same $\theta$ selections were used.

\begin{tabular}{|c|c|c|c|c|c|c|}
\hline Model & $\begin{array}{l}\text { Number of } \\
\text { nucleation } \\
\text { sites/particle } \\
(n)\end{array}$ & $\begin{array}{l}\text { Number of } \\
\text { different } \\
\text { particles } \\
(N)\end{array}$ & Mean $\theta$ & $\begin{array}{l}\text { Standard } \\
\text { deviation of } \\
\text { PDF } \sigma\end{array}$ & $\begin{array}{l}f(\theta)=b \\
\exp \left(\frac{-b_{1}}{\theta-b_{2}}\right)^{* *}\end{array}$ & $\begin{array}{l}F_{\text {fr }}=f\left(A_{1}, A_{2}, T\right) \\
\text { Eq. (12) }\end{array}$ \\
\hline \multicolumn{7}{|l|}{ Kaolinite* } \\
\hline $1 \theta$ & 1 & 1 & $88.8^{\circ}$ & - & - & - \\
\hline$\theta \mathrm{PDF}$ & - & 20 & $92^{\circ}$ & 0.089 & _- & - \\
\hline Soccer (int) & 80 & 1 & - & - & $\begin{array}{l}b=0.010455 \\
b_{1}=-9.647 \\
b_{2}=0.0922\end{array}$ & - \\
\hline Soccer (ext) & 50 & 20 & - & - & & - \\
\hline Deterministic & 1 & 1 & - & - & - & $\begin{array}{l}A_{1}=2.405 \times 10^{7} \mathrm{~cm}^{-2} \\
A_{2}=31.58^{\circ} \mathrm{C}\end{array}$ \\
\hline \multicolumn{7}{|c|}{$\mathrm{T} 1: 256.5 \mathrm{~K}>T>253.4 \mathrm{~K}$} \\
\hline $1 \theta$ & 1 & 1 & $52.5^{\circ}$ & - & - & \\
\hline Deterministic & 1 & 1 & - & - & - & $\begin{array}{l}A_{1}=3 \times 10^{7} \mathrm{~cm}^{-2} \\
A_{2}=16.5^{\circ} \mathrm{C}\end{array}$ \\
\hline
\end{tabular}

\begin{tabular}{|c|c|c|c|c|c|c|}
\hline \multicolumn{7}{|c|}{$\mathrm{T} 2: 262.5 \mathrm{~K}>T>260.25 \mathrm{~K}$} \\
\hline $1 \theta$ & 1 & 1 & $40^{\circ}$ & - & - & \\
\hline Deterministic & 1 & 1 & - & - & - & $\begin{array}{l}A_{1}=3 \times 10^{7} \mathrm{~cm}^{-2} \\
A_{2}=10.5^{\circ} \mathrm{C}\end{array}$ \\
\hline
\end{tabular}

* Based on Lüönd et al. (2010). Small deviations of the listed parameters as compared to the original once were introduced in order to predict a frozen fraction of $50 \%$ at $240 \mathrm{~K}$.

** Unlike Lüönd et al. (2010), who fitted the surface density of nucleation sites [ $\left.\mathrm{m}^{-2}\right]$, our parameters directly give the probability of a contact angle $\theta$ in the $\theta$ distribution on a particle surface for both soccer ball schemes.

The model using the $1 \theta$ scheme has been previously described in detail (Ervens et al., 2011). In brief, particles are treated on a moving size grid with the initial size determined by the discrete aerosol particle mass at that grid point. Cloud droplets form on a population of cloud condensation nuclei (CCN), composed of ammonium sulfate and insoluble material, in 11 size classes with a lognormal size distribution $\left(\sigma_{\mathrm{g}}=1.4, r_{\mathrm{g}}=0.04 \mu \mathrm{m} ; 0.02 \mu \mathrm{m}<D_{\mathrm{CCN}}<2 \mu \mathrm{m} ; N_{\mathrm{CCN}}=\right.$ $100 \mathrm{~cm}^{-3}$ ). We assume that a small fraction of these CCN can act as IN $\left(41^{-1} / 100 \mathrm{~cm}^{-3}=4 \times 10^{-5}\right.$ or $11^{-1} / 100 \mathrm{~cm}^{-3}$ for calculations at higher temperature).

Observed IN concentrations at these temperatures might be much higher $\left(\leq 1001^{-1}\right)$ (DeMott et al., 2010), but comprise only a small fraction of observed dust concentrations (e.g., Penner et al., 2009; Hoose et al., 2010). However, parcel model simulations have shown that IN concentrations of $\sim 101^{-1}<N_{\text {IN }}<5001^{-1}$ lead to the immediate glaciation of clouds (Eidhammer et al., 2009; Ervens et al., 2011), which contradicts observations of persistent mixed-phase clouds. The presence of higher IN concentrations in the atmosphere might be due to the separation of the two phases by precipitation of ice particles, which would limit the influence of the Bergeron-Findeisen process, or result from other selfregulating mechanisms (e.g., Harrington et al., 1999; Mor- rison et al., 2005, 2012). Since the parcel model does not include these additional processes, the sensitivity of IN concentration to the onset of cloud glaciation might be overestimated. Therefore, in order to explore the impact of different nucleation schemes in the mixed-phase cloud system, we chose the maximum IN concentrations in a way that the model predicts the coexistence of liquid and ice phases. In a first set of parcel model simulations, it is assumed that only a fraction of a single $\mathrm{CCN}$ size class $\left(D_{\mathrm{CCN}}=800 \mathrm{~nm}\right)$ act as ice nuclei with a concentration of $N_{\mathrm{IN}}=41^{-1}$; freezing of droplets formed on other particle sizes and ice nucleation by contact or deposition freezing are not considered. Simulations of monodisperse IN allow us to compare the parcel model results (Sect. 4.1) to the laboratory-based box model studies (Sect. 3). In a second set of simulations, a polydisperse IN distribution is assumed, where a fraction of all CCN size classes can act as IN, yielding the same total IN number concentration (Sect. 4.2).

Building on our previous study where we explored systematically the effects of various parameters $\left(N_{\mathrm{IN}}, N_{\mathrm{CCN}}, w\right.$, ice particle habits) on the ice/liquid partitioning in mixed-phase clouds (Ervens et al., 2011), we restrict our analysis here to some selected conditions in order to highlight the sensitivities of $N_{\text {ice }}$ and IWC to the different nucleation schemes. 
In the analysis of the model results, we discuss the differences in the predicted frozen fraction from the different nucleation schemes. Here, the fractions are always related to the (arbitrarily chosen), total number concentration of IN $\left(N_{\mathrm{IN}}=41^{-1}\right.$ or $N_{\mathrm{IN}}=11^{-1}$, respectively). We point out that this model framework was not set up to predict realistic ambient $N_{\text {ice }}$ concentrations, but rather to explore microphysical feedbacks in mixed-phase clouds, and to examine sensitivities to freezing onset in terms of different IN properties.

The nucleation schemes are the same as those used as in the box model, and the same random selection of contact angles is sampled from the PDFs of the soccer ball and $\theta \mathrm{PDF}$ schemes (Fig. 1; Table 1). Since the freezing probability generated by any scheme leads to an unmanageable number of ice classes during the course of the simulation, a more computationally efficient method is to establish a new ice size class when a discrete percentage (2.5\% for the simulations in this study) of a particle class, characterized by $D_{\mathrm{IN}}$ and $\theta$, is predicted to freeze. The choice of the relatively broad probability bin width can on occasion generate stepwise results at small time scales but the overall results are unchanged (Sect. 4.1). The description of the growth of ice particle includes the temperature-dependent evolution of their primary habits (Chen and Lamb, 1994; Sulia and Harrington, 2011). The parcel model simulations are initialized at $T=241 \mathrm{~K}$ and $\mathrm{RH}_{\mathrm{w}}=99 \%$, guided by the experimental conditions for which the nucleation schemes were derived. The simulations are chosen such that the parcel reaches the conditions as in the box model (Sect. 3.1) shortly after initialization. This provides the framework to explore the extent to which $N_{\text {ice }}$ evolution diverges over a wider range of temperatures during the evolution of drops and ice particles in a varying supersaturation field.

The freezing of IN that are immersed in a droplet or haze particle follows the description by Khvorostyanov and Curry (2004) and includes both immersion and condensation (deliquescence) freezing (Eqs. 1-7) since CNT treats the continuum of all supersaturation regimes. This approach allows stochastic ice nucleation under both subsaturated and supersaturated conditions with respect to water. The deterministic approach (Eq. 12) has been derived for conditions where kaolinite particles were immersed in water droplets. Thus, the only freezing mode occurring during the experiments was immersion freezing. Condensation freezing is dependent on the equilibrium supersaturation, and expressions such as Eq. (12) that were derived under non-equilbrium conditions at $S_{\mathrm{w}}>1$ may not be extrapolated to subsaturated conditions. Therefore, in our model studies, we assume $F_{\text {fr }}=0$ in the deterministic scheme when $S_{\mathrm{w}}<1$, i.e. below cloud base, and near cloud top if the water vapor supply is efficiently reduced by ice particle growth.

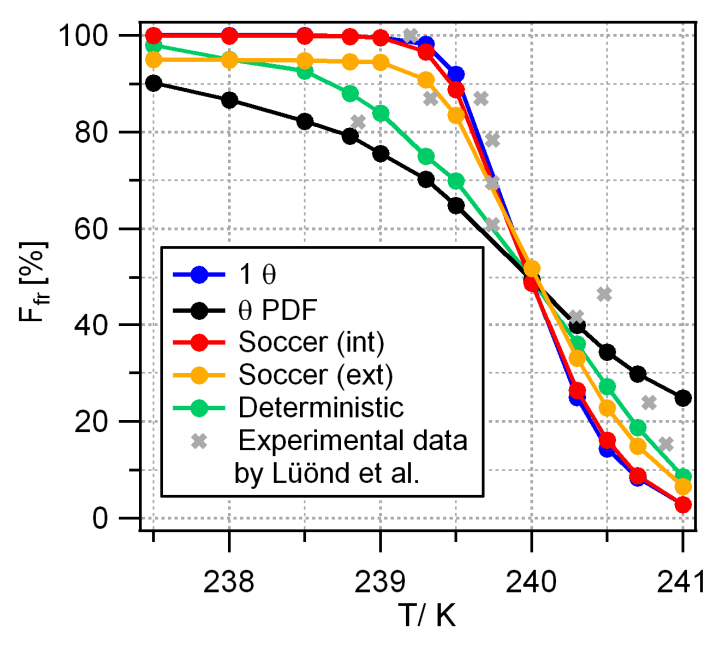

Fig. 2. Predicted frozen fraction $F_{\mathrm{fr}}$ as a function of temperature from box model calculations and experimental data by Lüönd et al. (2010) after $14 \mathrm{~s}$ simulation time and at $S_{\mathrm{W}}=0.2 \%$.

\section{Box model results}

\subsection{Agreement of nucleation schemes with laboratory studies}

We reproduced the calculations by Lüönd et al. (2010) to fit their experimental data using one of their selected particle sizes $\left(D_{\mathrm{IN}}=800 \mathrm{~nm}\right)$, albeit with slightly different parameters to describe the $\theta$ distributions by the stochastic models. These parameters, together with the assumed number of different $\theta$ in the $\theta$ PDF scheme and nucleation sites in the soccer ball schemes are summarized in Table 1. A slight shift in freezing temperature and $F_{\text {fr }}$ can be easily achieved by different random selections of contact angles even if the overall $\theta$ distribution is described by the same fit parameters. We note that the exact match between our parameters and those by Lüönd et al. (2010) for the different nucleation schemes is not of critical importance for the following analysis, but our discussion will instead build on the fact that all schemes predict similar $F_{\mathrm{fr}}$ over a temperature range of $237.5 \mathrm{~K}<T<241.0 \mathrm{~K}$, in agreement with the original experimental data (Fig. 2). Each point marks a single simulation of $14 \mathrm{~s}$ duration.

The conditions under which all schemes predict identical $F_{\text {fr }}\left(50 \%\right.$ at $T=240 \mathrm{~K}$ and $\left.S_{\text {ice }}=38.1 \%\right)$ are used as initial conditions for additional box model simulations to explore the temporal evolution of $F_{\mathrm{fr}}(t \leq 200 \mathrm{~s})$. Even though after $14 \mathrm{~s}$ all five schemes show $F_{\text {fr }}=50 \%$ for $D_{\mathrm{IN}}=800 \mathrm{~nm}$ (solid lines in Fig. 3), the slopes of the individual lines are different, affecting the evolution of $F_{\mathrm{fr}}$ at longer times. By definition, the deterministic scheme does not show any time dependence and appears as a horizontal line. The $1 \theta$ and the soccer (int) schemes show nearly identical $F_{\text {fr. }}$. This behavior 

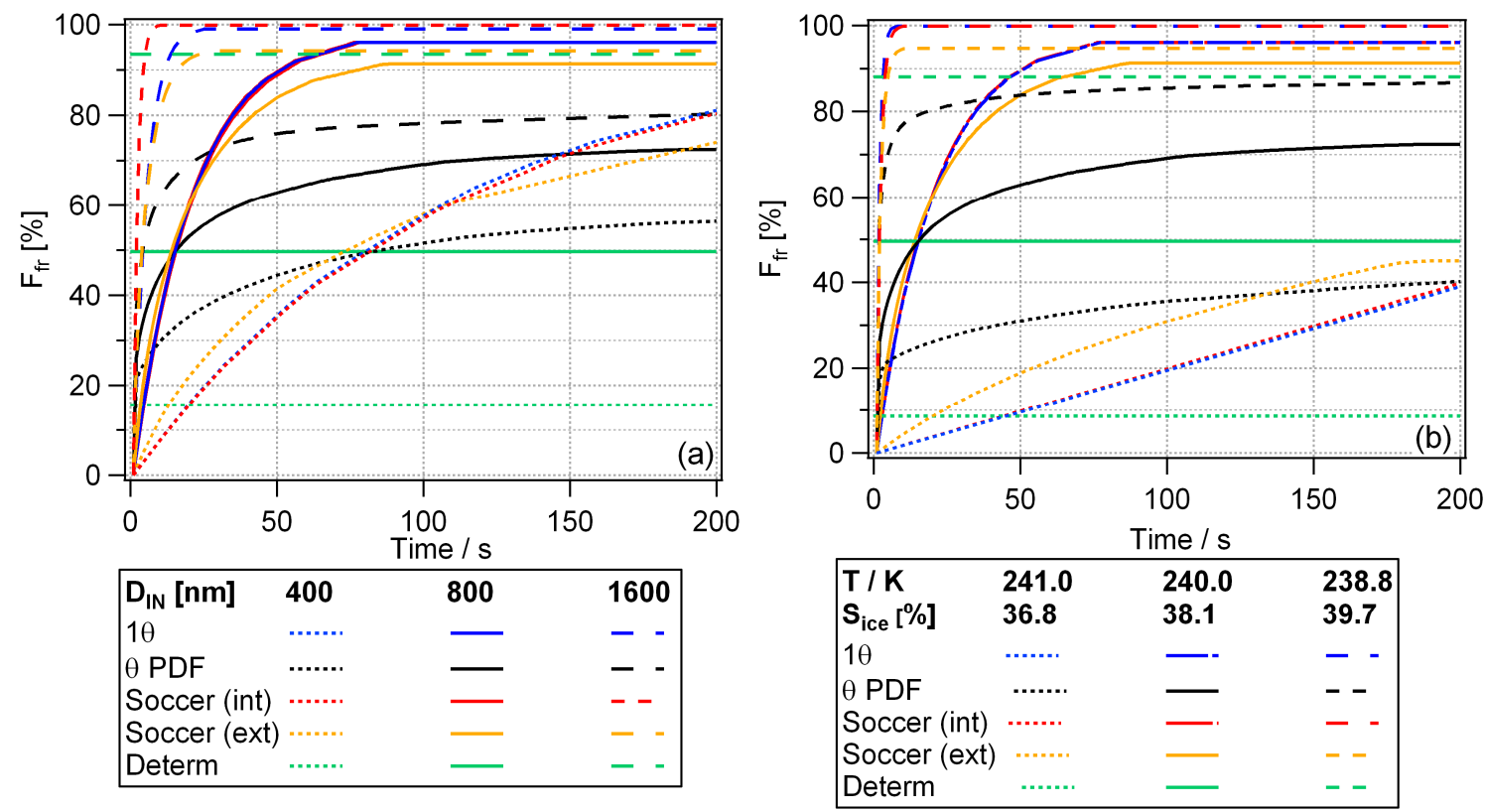

Fig. 3. Box model results for constant temperature and supersaturation. (a) Variation of the ice nuclei diameter $D_{\mathrm{IN}}\left(T=240 \mathrm{~K}, S_{\mathrm{ice}}=\right.$ $\left.38.1 \% ; S_{\mathrm{W}}=0.2 \%\right)$; (b) Variation of temperature and $S_{\text {ice }}\left(D_{\mathrm{IN}}=800 \mathrm{~nm}, S_{\mathrm{W}}=0.2 \%\right)$.

can be explained if

$P_{1 \theta} \sim P_{\text {socint }}$

i.e., if the overall nucleation rates in Eqs. (8) and (10) are approximately equal:

$J_{1 \theta} t \sim \sum_{j}^{n}\left(J_{j} S_{j} t\right)$

The distribution in the soccer (int) scheme exhibits a few small $\theta$ that are lower $\left(\theta_{\text {socint, } \min }=75^{\circ}\right)$ than the single value in the $1 \theta$ scheme $\left(\theta_{1 \theta}=88.8^{\circ}\right)$; the majority of the contact angles are larger than this single value. Large $\theta$ do not contribute significantly to $P_{\text {socint }}$ and, thus, the sum of $\left(J_{j} S_{j} t\right)$ is mostly dominated by contributions by the smallest contact angles. It is obvious that for different $\theta$ distributions and/or selections, the single $\theta$ that represents best the freezing behavior of these distributions will be different.

\subsection{Impact of IN diameter $D_{\mathrm{IN}}$ on frozen fraction $F_{\text {fr }}$}

According to Eq. (1), $J$ is directly proportional to the IN surface area $\left(D_{\mathrm{IN}}^{2}\right)$ and a complex function of $D_{\mathrm{IN}}$ in the calculation of $r_{\text {germ }}$ (Eq. 4). Thus, varying the IN size while all else is equal leads to different freezing probabilities. For simplicity, we assume here that the number of nucleation sites is the same on small and large particles. This approach implies that the size of the nucleation sites increases with IN size. While there is no physical basis for this assumption, and it might be more reasonable to scale the number of nucleation sites with particle surface, such a treatment would add more complexity to our conceptual model analysis since the IN ability of larger particles would increase not only due to size but also due to a statistically larger variety of nucleation sites.

For $D_{\mathrm{IN}}=1600 \mathrm{~nm}$, the $1 \theta$, and both soccer ball schemes predict $F_{\mathrm{fr}} \sim 100 \%$ after a few seconds (dashed lines in Fig. 3a). Such rapid, i.e. (nearly) time-independent freezing of all particles within a very short time has been interpreted as apparent singular freezing behavior (Niedermeier et al., 2011). The very high $F_{\text {fr }}$ for large $D_{\text {IN }}$ results in very small absolute and relative differences between the schemes. For smaller $D_{\mathrm{IN}}(400 \mathrm{~nm})$, all five schemes lead to smaller $F_{\mathrm{fr}}$ (dotted lines in Fig. 3a). As a result, the relative spread in $F_{\mathrm{fr}}$ for $D_{\mathrm{IN}}=400 \mathrm{~nm}$ amongst the five schemes is larger, and $F_{\text {fr }}$ differs by more than a factor of four after $200 \mathrm{~s}$, from $F_{\text {fr }} \sim 18 \%$ (deterministic) to $F_{\text {fr }} \sim 80 \%$ ( $1 \theta$ and soccer (int) schemes).

\subsection{Variation of temperature and $S_{\text {ice }}$}

A reduction in temperature leads to higher supersaturation $\left(S_{\text {ice }}\right)$ if $S_{\mathrm{w}}=$ const $=0.2 \%$, and $J$ increases exponentially with decreasing temperature (Eq. 1). Model results for the narrow range of $238.8 \mathrm{~K}<T<240 \mathrm{~K}$ and $39.7 \%>S_{\text {ice }}>$ $38.1 \%\left(D_{\mathrm{IN}}=800 \mathrm{~nm}\right)$ exhibit very similar trends (Fig. $\left.3 \mathrm{~b}\right)$ as compared to those achieved by varying $D_{\mathrm{IN}}$.

The results in Fig. 3 show that only for the specific conditions near the cross-over point in Fig. 2, do the different freezing schemes predict identical $F_{\text {fr. }}$. Thus, we caution against extrapolating the general agreement of all five schemes at prescribed laboratory conditions to a wider range 
of conditions. These simple box model simulations for wellconstrained conditions, i.e. time-invariant temperature, $S_{\text {ice }}$ and $S_{\mathrm{w}}$, suggest a potentially significant sensitivity of $F_{\mathrm{fr}}$ to nucleation scheme in a continuously cooling air parcel experiencing temporal evolution of temperature and supersaturation. The extent to which this is true is investigated in Sect. 4.

\section{Parcel model results}

\subsection{Monodisperse IN}

\subsubsection{Variation of updraft velocity}

The relative strength and time-dependence of cooling and condensation/deposition terms in Eq. (13) determine the vertical (or equivalently temporal) profile of $S_{\mathrm{w}}$ and $S_{\text {ice }}$. While condensation freezing can occur at subsaturated conditions $\left(\mathrm{RH}_{\mathrm{w}}<100 \%\right)$, immersion freezing requires the formation of droplets or sufficiently dilute particles prior to ice nucleation, i.e., $S_{\mathrm{w}}$ has to remain sufficiently high throughout the cloud in order to prevent droplets from evaporating. Since the model includes both condensation and immersion freezing, ice nucleation can continue if droplets evaporate as the remaining haze particles can form ice by condensation freezing if $S$ remains sufficiently high and the size of the ice germ exceeds the required threshold value (Khvorostyanov and Curry, 2000).

Figure 4a shows the vertical evolution of $N_{\text {ice }}$ as predicted by the five nucleation schemes for a cloud of $300 \mathrm{~m}$ depth in an air parcel rising with $w=50 \mathrm{~cm} \mathrm{~s}^{-1}$. Similar to the box model results, the $\theta$ PDF model leads to smaller $N_{\text {ice }}$ than the other stochastic models since only IN with sufficiently low $\theta$ form ice; the probability that such low $\theta$ are abundant on IN with multiple nucleation sites is much greater and thus $F_{\mathrm{fr}}$ is nearly $100 \%$ (related to the a priori set maximum IN concentration $N_{\mathrm{IN}}=41^{-1}$ ) for the soccer ball schemes. The fact that the $1 \theta$ scheme also shows $F_{\mathrm{fr}} \sim 100 \%$ in the lower parts of the cloud demonstrates that the single $\theta$ is sufficiently low to allow efficient freezing of all IN $\left(D_{\mathrm{IN}}=800 \mathrm{~nm}\right)$. In fact, closer inspection of results shows that the source of these ice particles can be partially ascribed to condensation freezing below the critical supersaturation of CCN. All stochastic schemes predict very rapid nucleation of a large $N_{\text {IN }}$ fraction near cloud base where the low temperature and sufficiently high supply of water vapor allow nucleation of IN with relatively low $\theta$. As already suggested by the box model studies, the range of $N_{\text {ice }}$ predicted by stochastic schemes is bounded by the $\theta$ PDF scheme for the smallest values and the $1 \theta$ and the soccer (int) scheme that predict the fastest and most efficient ice formation. The soccer (ext) scheme, which is likely the most realistic representation of IN surface properties, shows $N_{\text {ice }}$ in between these two limits. We note that the two soccer ball schemes might tend to converge if a higher number of nucleation sites on each particle sur- face were assumed, since the probability that particles include one of the rare "good nucleation sites" (low $\theta$ ) would increase. An "infinite" number of nucleation sites on all particles would lead to apparently singular freezing behavior (Niedermeier et al., 2011). However, since laboratory experiments could only be explained by different distributions of surface properties on particles within a population (Marcolli et al., 2007; Vali, 2008; Kulkarni et al., 2012), an external mixture with distinctly different contact angle distributions would seem an appropriate choice to represent the variability of surface properties.

$N_{\text {ice }}$ predicted based on the deterministic scheme reflects the continuous cooling rate of the air parcel during its ascent through the cloud $\left(S_{\mathrm{w}}>1\right)$. The evolution of IWC for the same simulation (Fig. 4b) can be explained by the trends in $N_{\text {ice }}$ : ice particles that nucleate near cloud base have the longest growth times. The gradual increase in $N_{\text {ice }}$ predicted by the deterministic scheme leads to the smallest IWC since relatively few ice particles start growing near cloud base. The ice size distribution in the $\theta$ PDF scheme comprises about $0.51^{-1}$ large particles that formed near cloud base; even though the final $N_{\text {ice }}$ is smaller in the $\theta$ PDF scheme, these early-nucleated particles lead to a similar IWC as compared to the $1 \theta$ and the soccer (int) schemes; in the latter cases the ice nucleation events occurred more gradually between $\sim 20 \mathrm{~m}$ and $50 \mathrm{~m}$ resulting in similar growth time scales and ice particle sizes. Thus, the agreement in IWC amongst the stochastic schemes is related to a combination of $N_{\text {ice }}$ and the duration of growth.

The amount of liquid water greatly dominates the total condensate, and the condensation term presents the most significant sink for supersaturation (Eq. 13). The IWC ( $0.003 \mathrm{~g} \mathrm{~kg}^{-1}$ at $h=300 \mathrm{~m}$ ) in all simulations represents less than $\sim 6 \%$ of the total condensate, $($ IWC + LWC) $\sim$ $0.05 \mathrm{~g} \mathrm{~kg}^{-1}$. Under such conditions, the LWC is not affected by the ice phase and the water vapor supply allows both droplets and ice particles to grow independently of one other (Ervens et al., 2011).

At smaller updraft velocities $\left(w=10 \mathrm{~cm} \mathrm{~s}^{-1}\right)$, the cooling term is smaller causing a lower maximum supersaturation near cloud base $\left(S_{\mathrm{w}, \max }=0.8 \% ; S_{\text {ice, } \max }=38 \%\right.$ at $h=25 \mathrm{~m}$; as opposed to $S_{\mathrm{w}, \max }=2.3 \%, S_{\mathrm{ice}, \max }=40.3 \%$ at $h=60 \mathrm{~m}$ for $w=50 \mathrm{~cm} \mathrm{~s}^{-1}$ ). With a weaker $S$ source term, the condensation sink to droplets plays a commensurately larger role in regulating $S_{\mathrm{w}}$ and $S_{\text {ice }}$ (Eq. 13). In general, the trend in the divergence of $N_{\text {ice }}$ between the different schemes is similar to the box model results (Fig. 3) that show a greater divergence and time-dependence for the stochastic schemes at low $S_{\text {ice }}(\propto$ low $w)$. All IWCs are greater for low $w$ and, in contrast to $N_{\text {ice }}$, more similar to each other than for high $w$ at a given height (Fig. 4b and d) because the lower $w$ implies longer growth times for particles, considering an equivalent cloud depth. The similar trends of $N_{\text {ice }}$ and IWC between the schemes at any given $w$ suggest that ice growth 

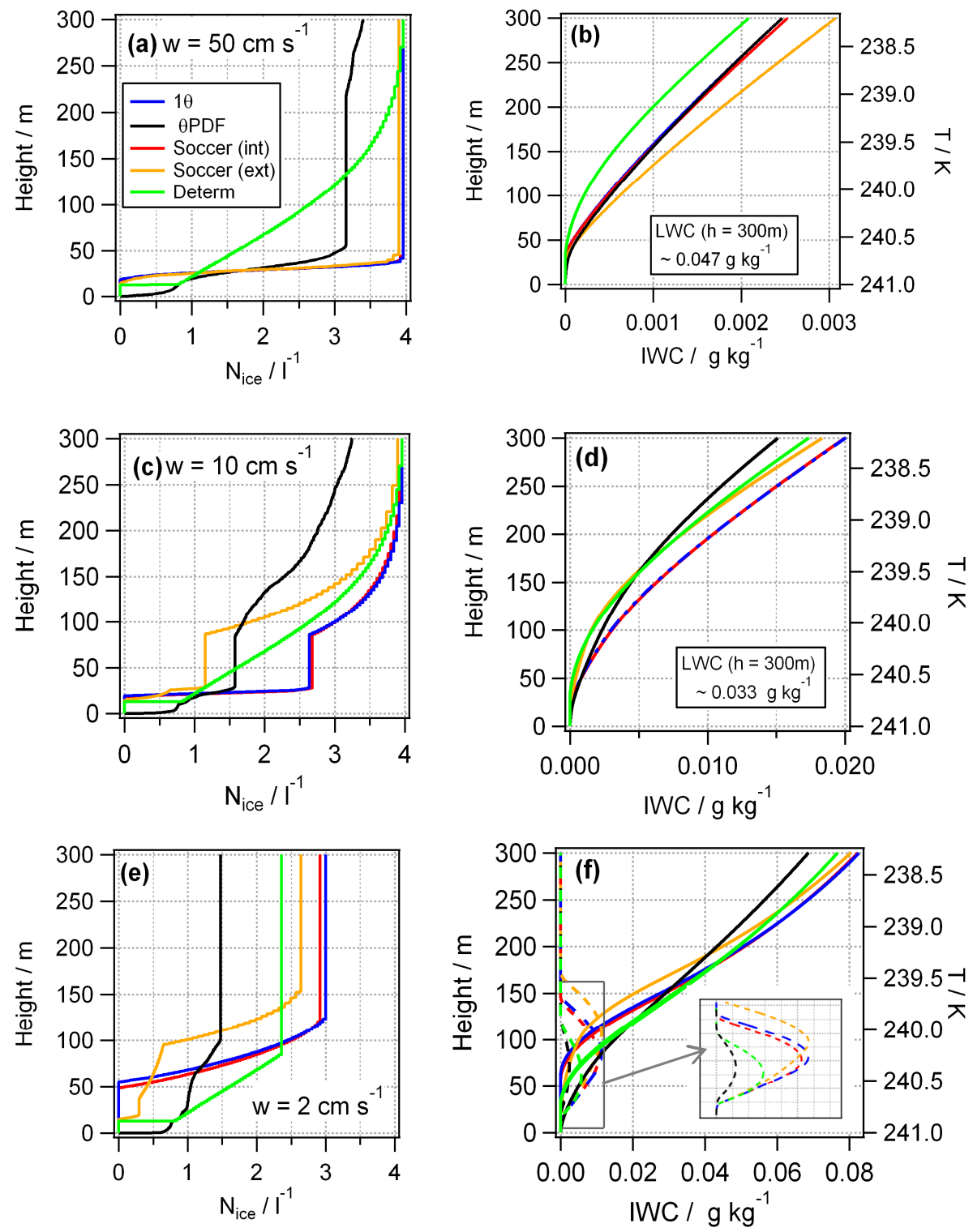

Fig. 4. Parcel model results using the five schemes as described in Fig. 1 and Table 1. (a, c, e) Evolution of $N_{\text {ice }}$ for an IN population with $N_{\text {IN }}=41^{-1}$ for three different updraft velocities $\left(w=50 \mathrm{~cm} \mathrm{~s}^{-1}, 10 \mathrm{~cm} \mathrm{~s}^{-1}, 2 \mathrm{~cm} \mathrm{~s}^{-1}\right)$ and a cloud depth of $300 \mathrm{~m}(238.2 \mathrm{~K}<T<241 \mathrm{~K})$. $(\mathbf{b}, \mathbf{d}, \mathbf{f})$ Ice water content IWC for the five nucleation schemes. The LWC in $(\mathbf{b}, \mathbf{d})$ is approximately the same for all schemes since the liquid phase is not significantly impacted by the ice phase. The dashed lines in (f) denote the liquid water content (LWC). The inset shows a zoom of the grey box. The stepwise behavior in the increase of $N_{\text {ice }}$ for the stochastic schemes is due to the probability steps we assume in order to avoid a high number of ice particle classes in the simulations (Sect. 2.3).

rates might be comparable and thus average particle sizes are similar.

The differences in vertical temperature profiles are small because $w$ dominates the cooling rate and differences in latent heating associated with condensation/deposition are small. Thus the evolution of $N_{\text {ice }}$ in Fig. $4 \mathrm{a}$ and c are almost identical for the deterministic scheme, which does not take into account any feedbacks of supersaturation on $N_{\text {ice }}$ (Eq. 12). Since at lower updraft velocity $S_{\mathrm{w}}>1$ is reached at slightly higher altitudes in the cloud, the first immersion freezing events occur somewhat later. However, since above this threshold the frozen fraction is dependent on temperature and only weakly on droplet radius, both simulations predict the same $N_{\text {ice }}$ evolution. Unlike in the box model studies, the deterministic scheme in the parcel model predicts similar $N_{\text {ice }}$ to the stochastic schemes (at cloud top) under the conditions in the current simulations.

Note that we have presented all model results at the same cloud thickness; however, ambient observations show that thinner clouds are usually observed in low-updraft regimes. 

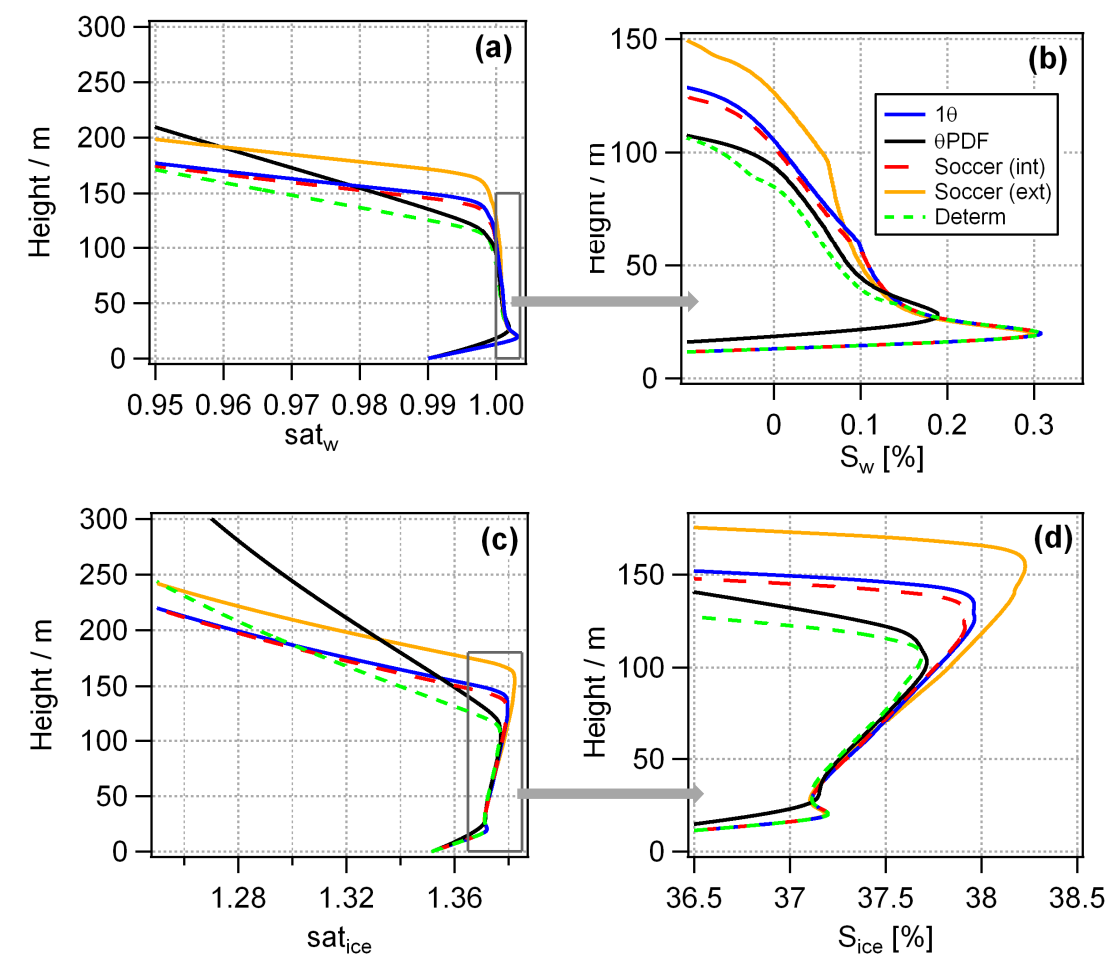

Fig. 5. Saturation sat and supersaturation $S[\%]$ with respect to $(\mathbf{a}, \mathbf{b})$ water and $(\mathbf{c}, \mathbf{d})$ ice for the simulations in Fig. $4 \mathrm{e}, \mathrm{f}\left(w=2 \mathrm{~cm} \mathrm{~s}^{-1}\right)$. They grey boxes in $(\mathbf{a}, \mathbf{c})$ are enlarged in (b) and (d), respectively, in order to show details of the maximum supersaturation near cloud base where initial ice nucleation occurs.

If one considers similar growth times, IWC is significantly smaller at the low $w$ (e.g., compare IWC at $300 \mathrm{~m}$ for $w=$ $50 \mathrm{~cm} \mathrm{~s}^{-1}$ to IWC at $60 \mathrm{~m}$ for $w=10 \mathrm{~cm} \mathrm{~s}^{-1}$ ) because of the lower $N_{\text {ice }}$.

\subsubsection{Initiation of the Bergeron-Findeisen process}

It has been discussed previously that low updrafts provide conditions in mixed-phase clouds that weaken the stability of the liquid phase as $S_{\mathrm{w}}$ is not sufficiently high to maintain continuous droplet growth (Korolev and Isaac, 2003; Ervens et al., 2011). Ice particles will grow at the expense of the droplets (Bergeron-Findeisen process) resulting in fully glaciated clouds.

The $1 \theta$ and the soccer ball schemes predict $N_{\text {ice }} \sim 31^{-1}$ above $h \sim 150 \mathrm{~m}$ at very low updraft velocity $\left(w=2 \mathrm{~cm} \mathrm{~s}^{-1}\right)$ (Fig. 4e). In contrast to conditions of higher $S$ (higher $w$ ), at low $w$ far fewer $\mathrm{CCN}$ are activated into droplets, resulting in a smaller condensation term and thus a relatively larger impact of vapor deposition on $S$. The $\theta$ PDF scheme initiates ice nucleation near cloud base $\left(N_{\text {ice }} \sim 0.61^{-1}\right)$; these ice particles limit the maximum supersaturation and thus further nucleation events. $S_{\text {ice }}$ and $S_{\mathrm{w}}$ reach lower maximum values and peak higher in the cloud as compared to the other schemes (Fig. 5a with zoom of the region near cloud base in Fig. 5b). Ice nucleation requires the formation of an ice germ above a threshold size; this critical germ size in- creases with decreasing $S$ (increasing $T$ ) which causes less efficient nucleation (Khvorostyanov and Curry, 2000, 2004; Curry and Khvorostyanov, 2012). Since condensation freezing is strongly dependent on $S_{\mathrm{w}, \text { eq }}$, the efficient consumption of water vapor by the growing ice particles prevents additional freezing events by increasing $r_{\text {germ }}$ and thus $N_{\text {ice }}$ remains constant despite relatively low $T$ as soon as $S$ decreases (vertical lines in Fig. 4e above $100 \mathrm{~m}$ ). Since the droplets are evaporating and converted into deliquesced particles, Eq. (12) is no longer applicable and $N_{\text {ice }}$ predicted by the deterministic scheme also ceases to increase. The decrease in $S_{\text {ice }}$ (Fig. 5c and d) is not as significant as that for $S_{\mathrm{w}}$ and the cloud always remains supersaturated with respect to ice. The evaporating droplets decrease the LWC and provide an additional source of water vapor for the further growth of ice particles, which explains the continuous increase in IWC (Fig. 4f).

$N_{\text {ice }}$ and $S_{\mathrm{w}}$ from the deterministic and $\theta \mathrm{PDF}$ schemes are similar to each other near cloud base; their early onset of freezing results in particles that have a distinct impact on $S$. Since the deterministic scheme does not take into account any feedbacks of $S$ on ice nucleation, $N_{\text {ice }}$ and IWC continue to increase, with commensurate influence on LWC loss (Fig. 4f, inset). In contrast, $N_{\text {ice }}$ asymptotes at about $100 \mathrm{~m}$ in the $\theta$ PDF scheme. For the other stochastic schemes, nucleation is delayed relative to the $\theta \mathrm{PDF}$ scheme. This leads to 
shorter growth time and smaller ice particles, which allows supersaturation to reach larger values higher in the cloud, and the liquid phase to persist longer (inset, Fig. 4f).

The initiation of the Bergeron-Findeisen process is closely linked to the stability and lifetime of mixed-phase clouds. Even though the parcel model is limited in its ability to simulate cloud stability and lifetime effects in detail due to its simplistic treatment of dynamic processes, it can be concluded that under conditions where the ice and liquid phases significantly impact supersaturation (and vice versa), detailed knowledge of the duration of ice nucleation events over a given temperature range is required to correctly predict mixed-phase cloud properties.

The different updraft regimes explored here represent three different scenarios in terms of impacts on cloud evolution. (i) The strong cooling rate at $w=50 \mathrm{~cm} \mathrm{~s}^{-1}$ generates a supersaturation in excess of a threshold supersaturation that is required to nucleate ice on nearly all IN at very short time scales. Thus, under such conditions detailed knowledge of $\theta$ distributions is likely less critical. (ii) The supersaturation profile at $w=10 \mathrm{~cm} \mathrm{~s}^{-1}$ covers the range of the onset supersaturations for the $\theta$ ranges throughout the IN population. Thus, subtle differences in $\theta$ (distributions) on IN translate into different $N_{\text {ice. }}$. Under those conditions, different nucleation schemes will lead to different ice nucleation spectra $\left(N_{\text {ice }}=f(S, T)\right)$ (Barahona, 2012). (iii) While in the latter two regimes there is very little impact of IWC on $S$, at very low updraft $\left(w=2 \mathrm{~cm} \mathrm{~s}^{-1}\right)$, the differences in $N_{\text {ice }}$ associated with the different temperature ranges over which nucleation occurs can impact cloud phase distribution due to significant feedback of IWC on $S$.

\subsubsection{Considerations on the temperature range of nucleation events}

\section{Temperature dependence of ice habit formation}

The nucleation schemes predict different temperature ranges over which nucleation events occur. While many nucleation events are predicted almost synchronously by the stochastic models over a narrow temperature range $\left(w=50 \mathrm{~cm} \mathrm{~s}^{-1}, h<50 \mathrm{~m}, 240.5 \mathrm{~K}<T<241.0 \mathrm{~K}\right.$; and $w=$ $\left.2 \mathrm{~cm} \mathrm{~s}^{-1}, h<150 \mathrm{~m}, 239.5 \mathrm{~K}<T<241.0 \mathrm{~K}\right)$, the deterministic scheme predicts nucleation throughout the depth of the cloud for all $w(237.7 \mathrm{~K}<T<241.0 \mathrm{~K})$. The rapid increase in $N_{\text {ice }}$ from IN populations with a single $\theta$ over such narrow temperature ranges has been compared to temperaturedependent trends of ice particles in the atmosphere and it has been concluded that only wider distributions of temperatures of the onset of freezing can explain these observations (Eidhammer et al., 2009; Welti et al., 2012).

In general, the temperature at which ice nucleation occurs determines the initial ice particle shape which is described by the inherent growth $\Gamma$ ratio of the ice particle and is equal to the ratio of the water vapor condensation

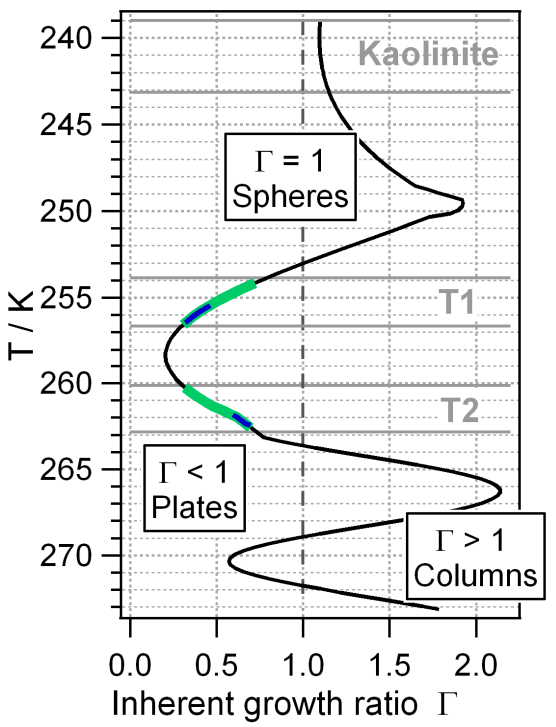

Fig. 6. Inherent growth ratio $\Gamma$ as a function of temperature (adapted from Chen and Lamb, 1994). The notation "columns, spheres, plates" refers to the shape the particle would attain if it were nucleated and grown primarily within that temperature range. The grey horizontal lines show temperature regimes for simulations where (i) IN composed of kaolinite nucleate ice and (ii) other IN are expected to nucleate ice (T1, T2). The blue and green shading within $\mathrm{T} 1$ and $\mathrm{T} 2$ marks the range where nucleation occurs if the $1 \theta$ or the deterministic schemes, is applied, respectively.

coefficients along the basal $(c)$ and prism $(a)$ axes (Hallett and Mason, 1958; Chen and Lamb, 1994; Lamb and Verlinde, 2011). At the temperature range relevant for immersion/condensation freezing of kaolinite $(T \sim 243 \mathrm{~K}), \Gamma$ is near unity, i.e. ice particles are approximately spherical (Fig. 6). At higher temperatures, $\Gamma$ might differ significantly from unity and strongly impact the evolution of the aspect ratio $(\varphi=c / a)$ of an ice particle that develops from the initial geometry, prescribed by $\Gamma$, towards a geometry as predicted at a given temperature. Such more extreme habits result in highly nonlinear growth rates of ice particles in different temperature regimes since non-spherical particles grow faster than spheres of the same mass (Mason, 1953; Takahashi et al., 1991). Atmospheric observations reveal that ice is sometimes formed at habit-prone temperatures and model studies have shown the need of the detailed description of ice growth rates as they significantly affect the phase partitioning in mixed-phase clouds (Avramov and Harrington, 2010; Sulia and Harrington, 2011). Ice nucleation at such temperatures implies the presence of more efficient IN than kaolinite, such as biological particles (Schnell and Vali, 1976; Christner et al., 2008) or other types of dust (Roberts and Hallett, 1968; DeMott et al., 2003; Möhler et al., 2006). 

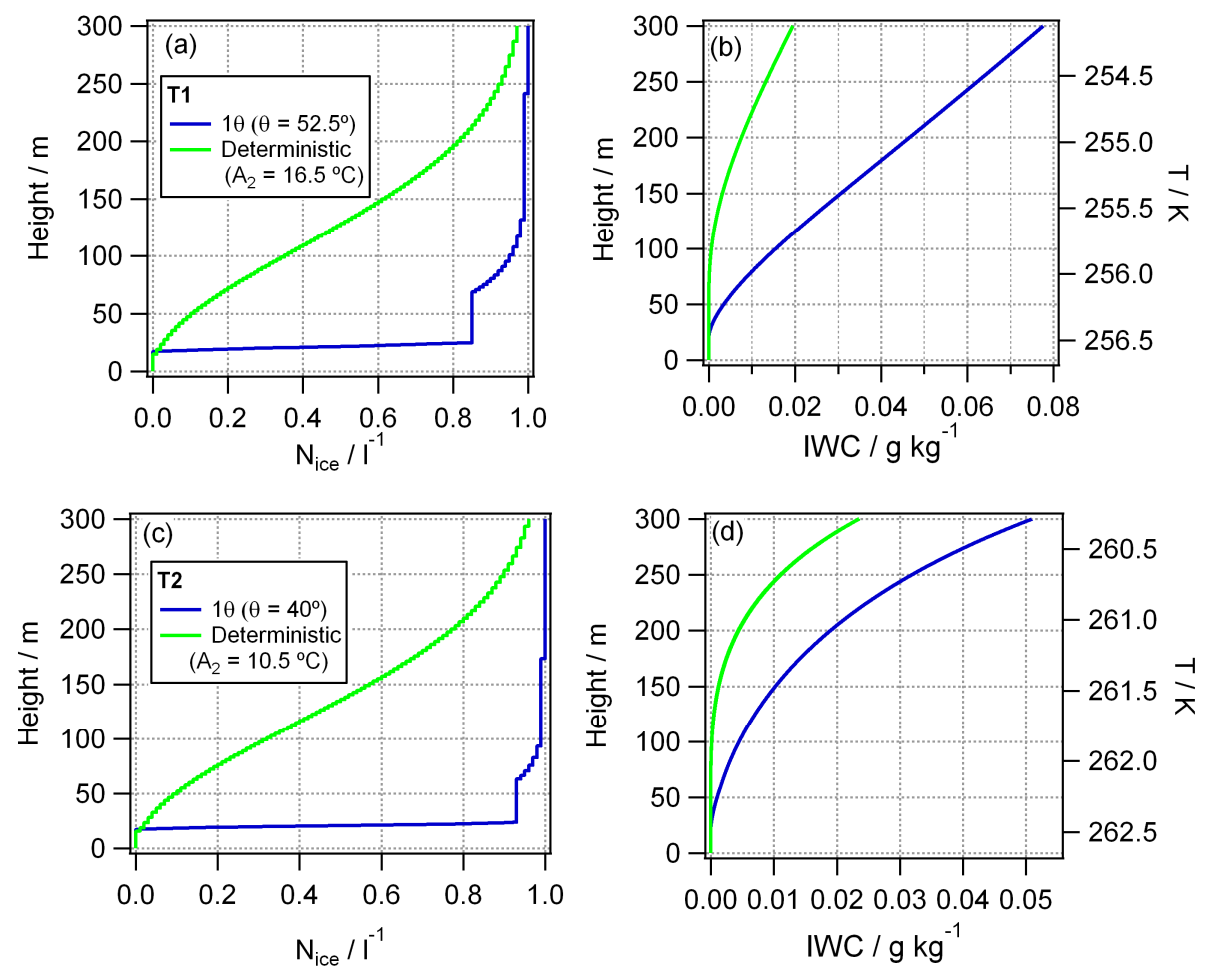

Fig. 7. Evolution of the ice number concentration $N_{\text {ice }}$ of an IN population with $N_{\mathrm{IN}}=11^{-1}$ and ice water content IWC for heterogeneous freezing in temperature regime T1 $(\mathbf{a}, \mathbf{b})$ and T2 (c, d) as marked in Fig. 6. For the two temperature regimes, different parameter sets $\left(\theta, A_{1}\right.$, $A_{2}$ ) were applied (Table 1).

\section{Model studies at higher temperatures (T1 and T2)}

The temperature range of freezing of kaolinite particles as determined by Lüönd et al. (2010) is near the threshold of homogenous freezing. Many laboratory studies and observations have shown that heterogeneous freezing occurs at higher temperatures (e.g., DeMott et al., 2003; McFarquhar et al., 2007; Chen et al., 2008; Niemand et al., 2012; Pinti et al., 2012). However, for IN freezing at these higher temperatures a consistent set of parameters for all five schemes as derived for kaolinite is not available. Notwithstanding the lack of such data sets from laboratory experiments for IN that nucleate ice at $\sim 253 \mathrm{~K}<T<\sim 263 \mathrm{~K}$, in the following, we explore effects of nonlinear growth rates on $N_{\text {ice }}$ and IWC of ice particles nucleated at these temperatures. These simulations demonstrate effects in a more conceptual way and add other potential aspects that could lead to convergence or divergence in predicted cloud properties due to different temperature ranges of ice nucleation. We have chosen two temperature ranges ( $\mathrm{T} 1$ and $\mathrm{T} 2$ ) that are again covered by an air parcel rising for $300 \mathrm{~m}$ in such a way that with decreasing $T, \Gamma$ approaches unity in the former, and shows the opposite trend in the latter (Fig. 6). We limit this analysis to the $1 \theta$ and deterministic schemes and adjust the two parameter sets $\left(\theta, A_{1}, A_{2}\right.$, Table 1$)$ for the temperature regimes $\mathrm{T} 1$ and $\mathrm{T} 2$, respectively, in order to predict first nucleation events at the same height in the cloud and temporal evolution of $N_{\text {ice }}$ as for the results discussed for kaolinite (Fig. 4). Model conditions are chosen such that the Bergeron-Findeisen process does not occur $\left(N_{\mathrm{IN}}=11^{-1}, w=10 \mathrm{~cm} \mathrm{~s}^{-1}\right)$ in order to exclude nonlinear increases in IWC due to rapid changes in phase partitioning.

Similar to the findings in Fig. 4, in T1 most nucleation events predicted by the $1 \theta$ scheme occur near cloud base whereas continuous ice nucleation is predicted over the depth of the cloud for the deterministic scheme (Fig. 7a). The resulting IWCs differ by a factor of $\sim 4(h=300 \mathrm{~m})$ between the two schemes (Fig. 7b). The evolution of $N_{\text {ice }}$ in the temperature regime $\mathrm{T} 2$ is very similar to that in $\mathrm{T} 1$ (Fig. 7c), as pre-determined by the parameter sets $\theta$ and $A_{2}$ for the respective temperature range (Table 1). However, the resulting IWC from the two schemes are much more similar in T2 and only differ by a factor of two (Fig. 7d). The reason lies in the behavior of $\Gamma$ in the two different temperature regimes and the different temperature ranges over which freezing occurs. For the higher temperature T2, the $1 \theta$ scheme predicts freezing occurring over a very narrow temperature range with an initial inherent growth ratio $\Gamma \sim 0.7$ (blue shading in Fig. 6). For the deterministic model freezing occurs over a much larger temperature range (green shading) with $\Gamma$ becoming progressively smaller than 0.7 . Such particles with smaller initial $\Gamma$ are less spherical and grow faster than the 
high number of particles that are predicted by the $1 \theta$ scheme to freeze near cloud base $(T \sim 263 \mathrm{~K} ; \Gamma \sim 0.7)$, resulting in small IWC differences. In T1, ice particles predicted by the $1 \theta$ scheme near cloud base benefit from smaller $\Gamma(\sim 0.3)$ and, thus, have higher growth rates throughout the cloud since they are more plate-like due to their initial geometry than particles that nucleate at lower temperature. For the deterministic model, progressively colder temperatures result in an increase in $\Gamma$ leading to more spherical particles with smaller growth rates. Thus, the many non-spherical particles predicted by the $1 \theta$ scheme not only have longer growth times but also higher growth rates, which results in a larger differential in IWC between the two nucleation schemes.

The tendency for IWC to often scale with $N_{\text {ice }}$ (Figs. 4 and 7) suggests that ice particle sizes are relatively uniform amongst the different schemes. Indeed, additional analysis of the results in Fig. 4 shows that ice particle sizes for all five schemes cover a similar size range of $\sim 10 \mu \mathrm{m}<D_{\text {ice }}<$ $250 \mu \mathrm{m}$ (at $200 \mathrm{~m}$, not shown). This relatively broad range is due to the large spread in onset temperatures of freezing for the monodisperse IN which implies different growth time scales for ice particles nucleated at different times and thus reflects the stochastic and temperature-dependent nature of the freezing process. A more thorough analysis of the size distributions from these simulations is not particularly meaningful since ambient IN distributions are unlikely to be monodisperse. Nevertheless, the assumption of monodisperse IN has allowed us to separate effects of different nucleation schemes on $N_{\text {ice }}$ without having to deal with potential effects due to different IN sizes.

\subsection{Parcel model studies: polydisperse IN}

\section{Ice/liquid distribution}

Since the box model results in Sect. 3 suggested a great sensitivity of $F_{\text {fr }}$ to IN size if $D_{\mathrm{IN}}$ is varied by a factor of two, we performed additional simulations $\left(w=10 \mathrm{~cm} \mathrm{~s}^{-1}\right)$ where we assume that a fraction of each of the $11 \mathrm{CCN}$ size classes $\left(0.02 \mu \mathrm{m}<D_{\mathrm{CCN}}<2 \mu \mathrm{m}\right)$ can form ice; the total IN number is the same as in the simulations discussed in Sect. 4.1 $\left(N_{\mathrm{IN}}=41^{-1}\right.$ at $T \sim 243 \mathrm{~K}$ (kaolinite); $N_{\mathrm{IN}}=11^{-1}$ at $\mathrm{T} 1$ and T2). Even though typical atmospheric IN (e.g., dust, biological particles) might not exhibit sizes as low as $0.02 \mu \mathrm{m}$, these simulations allow us to explore the role of IN sizes in a conceptual framework. These exercises tie in with our earlier work where we showed that the temporal (vertical) change of LWC as a function of the ratio of the integral ice capacitance to the integral droplet radius can be considered a measure of the stability of a mixed-phase cloud (Ervens et al., 2011).

$N_{\text {ice }}$ shows a much greater discrepancy between the five schemes than the results for monodisperse IN (cf. Figs. 4b and 8a). Since most IN are smaller than $800 \mathrm{~nm}$, all schemes show much lower $N_{\text {ice }}$. While in the simulations of monodisperse IN, the $1 \theta$ and the soccer (int) schemes showed nearly identical $N_{\text {ice }}$ for all updraft velocities, the difference in $N_{\text {ice }}$ resulting from different IN size classes is significant for these two schemes. As explained above, for a given size the predicted freezing probabilities might be equal if Eqs. (14) and (15) hold true. However, since $J$ is a complex function of $D_{\text {IN }}$ (Eqs. 1-6), $P_{1 \theta}$ and $P_{\text {socint }}$ do not scale proportionally with $D_{\text {IN }}$ so that one no longer expects agreement. The strong size dependence of $F_{\mathrm{fr}}$ in the deterministic approach (Eq. 12) results in very small $N_{\text {ice }}$ for the selected initial size distribution. The trend in $N_{\text {ice }}$ is reflected in IWC with the exception of the $\theta \mathrm{PDF}$ scheme higher in the cloud owing to high $N_{\text {ice }}$ near cloud base.

The evolution of LWC shows that under these model initial conditions the choice of the nucleation scheme might have bearing on the stability of the cloud (Fig. 8b). The soccer (int) scheme predicts the largest frozen fraction and IWC and thus LWC is clearly affected, as evidenced by a deceleration of growth with increasing height. This sensitivity to the different nucleation schemes is more clearly depicted by the ratio IWC/LWC (Fig. 8c): in situations where IWC $\sim 0.5 \mathrm{LWC}$ there is noticeable evidence of cloud droplets evaporating due to the Bergeron-Findeisen process.

The adiabatic conditions in the parcel model determine the total amount of condensate (IWC + LWC) which is smaller at lower temperatures. This is clearly seen in the significantly smaller IWC + LWC for the colder regime compared to the warmer regimes (T1 and T2) (cf. Fig. 8d and e and Fig. 7). Ratios of IWC/LWC are notably smaller than at the colder temperature (cf. Fig. 8c and f) and, thus, clouds are expected to be more stable. The similar evolution of $N_{\text {ice }}$ at T1 and T2 is due to the parameter choices for these simulations. (Recall that $\theta_{1 \theta}$ and $A_{2}$, Table 1 , were adjusted in order to produce similar vertical $N_{\text {ice }}$ profiles as compared to the corresponding schemes at $T \sim 243 \mathrm{~K}$.) Thus, also at these higher temperatures, the differences in $N_{\text {ice }}$ between the nucleation schemes are much greater for a polydisperse IN distribution as compared to results from monodisperse IN due to the different dependencies of $F_{\mathrm{fr}}$ on $D_{\mathrm{IN}}$.

\subsection{Size distribution of ice particles}

Ice size distributions from the above simulations for polydisperse IN at $h=200 \mathrm{~m}$ are shown in Fig. 9a (lower temperatures) and $9 \mathrm{~b}$ (higher temperatures, $\mathrm{T} 1$ and $\mathrm{T} 2$ ). The equivalent diameter of a (non-spherical) ice particle is used to represent the diameter of a sphere with the same mass. Since the number of ice size classes in the model is huge (several thousand classes for the externally-mixed $\theta$ PDF and soccer (ext) schemes) but each ice class only contains a very small number of particles, size distributions in Fig. 9 are created by sorting all ice particles into ten equally-spaced size bins. The size range of nearly spherical ice particles that grew at low temperatures is very similar for all nucleation schemes (Fig. 9a), which is consistent with the trend of $N_{\text {ice }}$ and IWC to scale (Fig. 8a). The higher IWC in the soccer (int) scheme (Fig. 8b) 

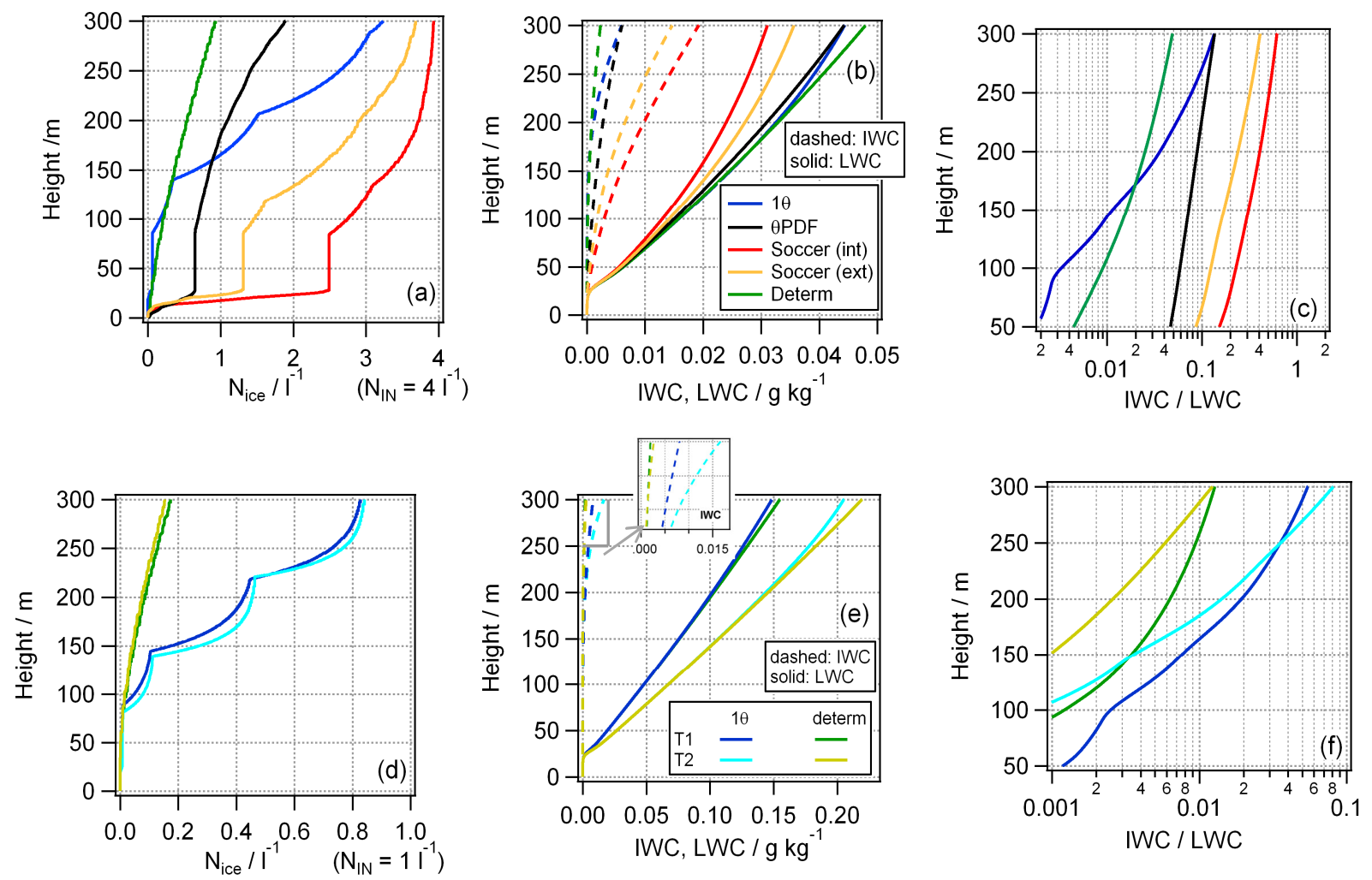

Fig. 8. Parcel model results of (a, d) the evolution of the ice number concentration $N_{\text {ice }}$ of an IN population with $N_{\text {IN }}$, (b, e) IWC, LWC, and $(\mathbf{c}, \mathbf{f})$ IWC/LWC assuming a polydisperse IN size distribution. The upper panel corresponds to immersion/condensation freezing of kaolinite; the bottom panel includes results for simulations at temperature regimes $\mathrm{T} 1$ and $\mathrm{T} 2$.

is consistent with the high number of ice particles that nucleated near cloud base. Even though these particles slightly reduce the supersaturation, the growth rates of ice particles are not significantly affected as compared to those predicted in the other schemes, resulting in similar particle sizes. In general, the change in $S$ (Eq. 13) is mostly controlled by the numerous small droplets (LWC) and to a smaller extent by the much fewer ice particles if both phases grow independently of one other. Only under conditions of the BergeronFindeisen process (e.g., near cloud top in the soccer (int) scheme), does efficient deposition of water vapor on ice particles represent a major sink for supersaturation. Under those conditions, the ice particles benefit from the evaporation of droplets as an additional source of water vapor. The consistency in size range between the $1 \theta$ and deterministic scheme is also evident in the simulations at T1 and T2 (Fig. 9b). At the same temperature, the size range is similar for the two nucleation schemes. On the other hand, the size range differs between the $\mathrm{T} 1$ and $\mathrm{T} 2$ regimes because in $\mathrm{T} 1$ particles grow more efficiently owing to their more extreme habits in T1 (Sect. 4.1.3).

The capacitance $C$ of a spherical particle equals particle radius; for non-spherical particles capacitance is determined by the curvature of the particle (e.g., McDonald, 1963). The integral capacitance is the number-weighted capacitance in each size class $i, \Sigma_{i}\left(N_{\mathrm{ice}, i} \cdot C_{i}\right)$. Many different combinations of individual $\left(N_{\text {ice }, i} \cdot C_{i}\right)$ can yield the same integrated value and thus affect the evolution of IWC and its impact on LWC to similar extents (Ervens et al., 2011). Figure 9c and d display $N_{\text {ice }}$ as a function of the mean capacitance $C_{\text {mean }}$ (average value over all $C_{i}[\mu \mathrm{m}]$ within the ice particle population). The contours show lines of equal integral capacitance $\left[\mu \mathrm{ml}^{-1}\right]$. The distributions of (nearly) spherical particles show a very similar $C_{\text {mean }}$ for all schemes over the depth of the cloud (color-coding indicates height) (Fig. 9c). Both the size distributions and the mean capacitances show that the particle sizes do not differ much between the different schemes for the conditions when both phases grow independently of one other. This consistency is similar to that found in our previous study where we showed that different $N_{\text {ice }}$ result in similar equivalent diameters for the same growth time scales for wide ranges of the $N_{\mathrm{IN}}, w$, and $T$ parameter spaces (Ervens et al., 2011). It was concluded that the vapor supply is sufficient to allow particle growth without competition for water vapor. The integral capacitance differs by a factor of seven between the soccer (int) [3, in Fig. 9c] and the deterministic [5, in Fig. 9c] scheme due to the different $N_{\text {ice }}\left(C_{\text {mean, soccer(int) }} \sim\right.$ 

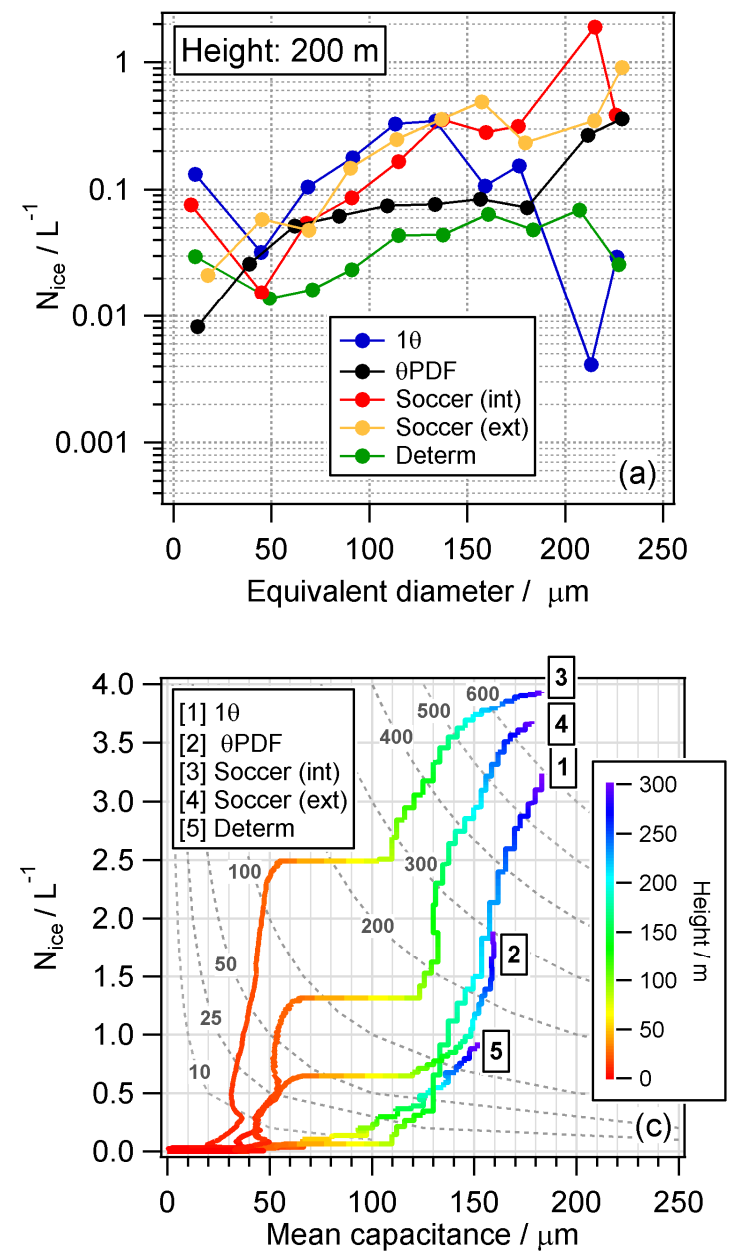
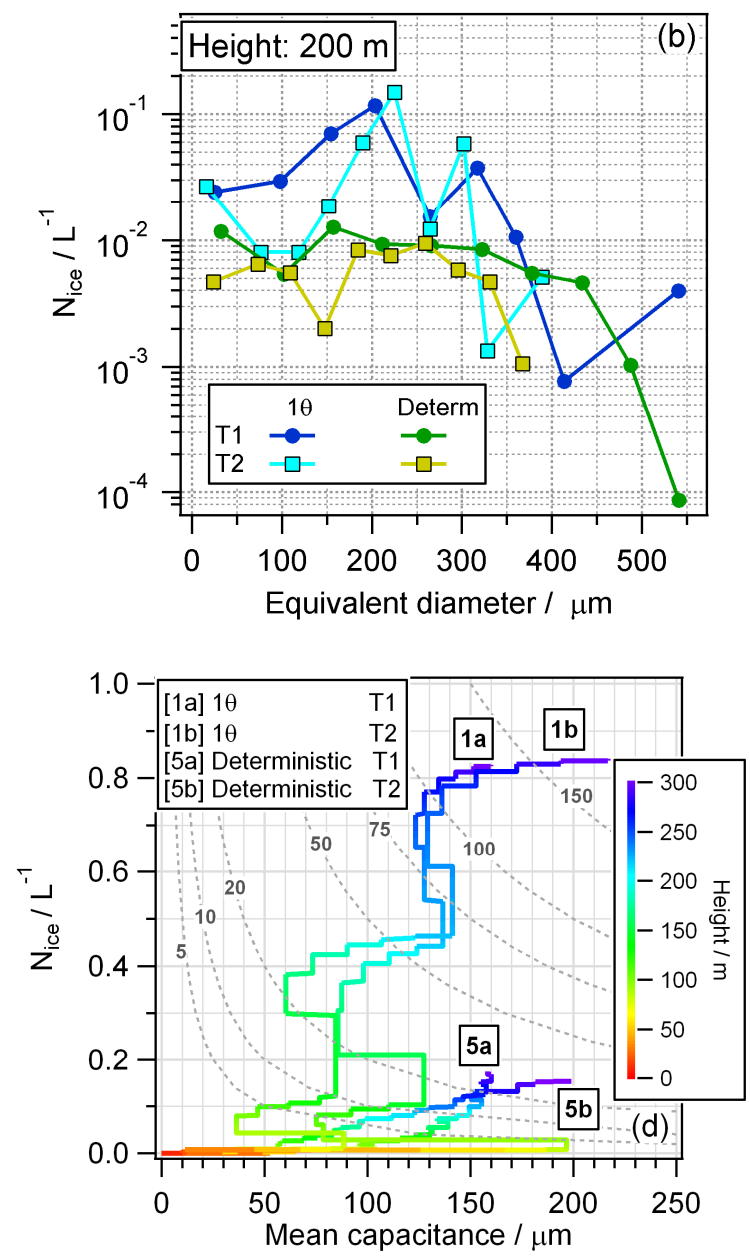

Fig. 9. Parcel model results for polydisperse IN distributions: (a, b) ice size distributions $(h=200 \mathrm{~m})$ and (c, d) details on mean and integral ice capacitance. Grey contours show lines of equal capacitance; numbers on the contours denote integral capacitance $N_{i} C_{i}\left[\mu \mathrm{m} 1^{-1}\right.$ ]. $(\mathbf{a}$, c) $T \sim 243 \mathrm{~K}$ (kaolinite). (b, d) Temperature ranges $\mathrm{T} 1$ and $\mathrm{T} 2$.

$\left.700 \mu \mathrm{ml}^{-1} ; C_{\text {mean, determ }} \sim 100 \mu \mathrm{ml}^{-1}\right)$. At the higher temperatures ( $\mathrm{T} 1$ and $\mathrm{T} 2$ ) the vertical evolution of the mean capacitance is not as consistent as for the more uniform spherical particles at the lower temperatures since the different initial particle shapes and resulting growth rates lead to different capacitances throughout the ice population. However, the differences in $C_{\text {mean }}$ between the two different nucleation schemes $\left(C_{\text {mean, } 1 \theta} / C_{\text {mean, determ }} \sim 160 / 20\right)$ are very similar to those at $T \sim 243 \mathrm{~K}$.

This analysis suggests that the choice of the nucleation scheme does not affect resulting particle growth rates and sizes to a significant extent but that the differences in resulting integral capacitance are mostly ascribed to differences in $N_{\text {ice }}$ that form at different temperatures. Thus, the choice of the nucleation scheme has the most significant impact on $N_{\text {ice }}$ by determining the timing of nucleation events, subsequent duration of ice growth, and the temperature range over which ice growth occurs. For a given temperature regime, the nucleation scheme has little influence on growth rates of ice particles as long as the cloud is supersaturated with respect to ice.

\section{Conclusions}

Model simulations have been performed to explore the sensitivity of properties of mixed-phase clouds to different nucleation schemes for immersion and condensation freezing of particles that are assumed to exhibit similar surface properties as derived for kaolinite particle in laboratory experiments. The five nucleation schemes cover time-dependent (stochastic) freezing of particle populations of (i) identical surface properties with a single contact angle $(1 \theta)$, (ii) an external mixture of surface properties $(\theta \mathrm{PDF})$; a distribution of contact angles of particle surfaces of (iii) internally mixed (soccer (int)) and (iv) externally mixed particles (soccer (ext)) and (v) a time-independent, singular freezing behavior (deterministic scheme). 
A box model was applied in order to mimic laboratory experiments for monodisperse $(800 \mathrm{~nm})$ IN that were previously used to derive parameters for the different nucleation schemes (Lüönd et al., 2010). This provides realism to the parameter choices for the subsequent modeling exercises. Sensitivity studies show that the frozen IN fractions from the different schemes that are very similar over short time scales diverge significantly for extended time scales, as well as for different conditions such as IN diameter, supersaturation and temperature.

The schemes were implemented into a parcel model that takes into account detailed microphysical feedbacks of droplet and ice particle growth on supersaturation. During the early stages of cloud evolution, frozen particles are formed by condensation freezing at (water) subsaturated conditions predicted by the stochastic schemes whereas the deterministic scheme is only applicable to supersaturated conditions with respect to water. When the supersaturation in the cloud is sufficiently high to result in droplet activation or sufficiently dilute particles, freezing occurs through the immersion mode. At high updraft velocities, the strong cooling rates allow nearly all the equally-sized $(800 \mathrm{~nm}) \mathrm{IN}$ to nucleate ice, with only weak dependence on their $\theta$ distributions. At lower updraft velocities (lower supersaturations), the choice of the nucleation scheme leads to the greatest differences in predicted $N_{\text {ice }}$. The deterministic approach only depends on temperature and is time-independent; thus $N_{\text {ice }}$ is not regulated by the cooling rate and feedbacks of $N_{\text {ice }}$ and LWC on supersaturation, leading to the highest $N_{\text {ice }}$ in supersaturation-limited scenarios. The sensitive relationship between ice and supersaturation tends to initiate the Bergeron-Findeisen process (all else equal) in low updraft regimes. Depending on the choice of the nucleation scheme, the demise of the liquid phase will be initiated at different times/heights in a cloud since nucleation events occur over different temperature ranges.

At higher temperatures, differences in the temperature range of nucleation events not only translate into different temporal $N_{\text {ice }}$ profiles but also into different initial particle shapes (inherent growth ratios). Exploratory simulations show that such differences in initial particle geometry as predicted by the $1 \theta$ or deterministic scheme, respectively, can translate into different growth rates that can lead to either amplification or reduction in predicted differences in IWC.

Finally, parcel model simulations that consider a polydisperse IN population show that the different parameterizations of $\theta$ distributions and time-dependencies are highly sensitive to IN size and lead to great differences in predicted ice number concentrations between the different schemes. The analysis of parameters that characterize the ice size distributions, i.e. the mean and integral capacitances, show that the differences in the latter are mostly determined by differences in ice number concentration and less by the spread in ice particle sizes. The IWC tends to scale with $N_{\text {ice }}$, since ice particle sizes are very similar from one scheme to the other. As long as the water phase exists, condensation is the primary loss term for supersaturation. Under these conditions, and at the low ambient $N_{\text {ice }}$, ice particles grow by diffusion without competition from other particles.

The absence of a dynamical framework, collection, and sedimentation in the current study makes it difficult to assess just how much impact these schemes would have on ice number concentration and total ice mass and makes a comparison of predicted ice number concentration to observations difficult. Some insight can be obtained from Kulkarni et al. (2012), who used a two-dimensional, cloud-resolving model to show that differences in $N_{\text {ice }}$ as predicted from the $1 \theta$ and the $\theta$ PDF scheme result in significant differences in IWC, depending on the choice of parameters. It is therefore likely that the additional schemes tested here will have significant influence.

In summary, the large differences in the evolution of the frozen fraction and related parameters from the five nucleation schemes reveal that the consistency in predicted frozen IN fraction suggested by recent laboratory experiments is restricted to a very narrow range of conditions. The extrapolation of these schemes to a wide range of atmosphericallyrelevant conditions can lead to great discrepancies in predicted cloud-relevant parameters if the cloud covers conditions where ice nucleation is sensitive to surface properties (contact angle distributions). Our sensitivity studies show the urgent need for better constraints of the physicochemical properties that determine the freezing behavior of IN. Laboratory experiments should be designed to refine the appropriateness of different nucleation schemes for various aerosol types and conditions.

Acknowledgements. The authors acknowledge support from NOAA's Climate Goal.

Edited by: T. Koop

\section{References}

Alpert, P. A., Aller, J. Y., and Knopf, D. A.: Initiation of the ice phase by marine biogenic surfaces in supersaturated gas and supercooled aqueous phases, Phys. Chem. Chem. Phys., 13, 44, 19882-19894, 2011.

Archuleta, C. M., DeMott, P. J., and Kreidenweis, S. M.: Ice nucleation by surrogates for atmospheric mineral dust and mineral dust/sulfate particles at cirrus temperatures, Atmos. Chem. Phys., 5, 2617-2634, doi:10.5194/acp-5-2617-2005, 2005.

Avramov, A. and Harrington, J. Y.: Influence of parameterized ice habit on simulated mixed phase Arctic clouds, J. Geophys. Res., 115, D03205, doi:10.1029/2009jd012108, 2010.

Barahona, D.: On the ice nucleation spectrum, Atmos. Chem. Phys., 12, 3733-3752, doi:10.5194/acp-12-3733-2012, 2012.

Bigg, E. K.: The formation of atmospheric ice crystals by the freezing of droplets, Q. J. Roy. Meteor. Soc., 79, 342, 510-519, doi:10.1002/qj.49707934207, 1953. 
Broadley, S. L., Murray, B. J., Herbert, R. J., Atkinson, J. D., Dobbie, S., Malkin, T. L., Condliffe, E., and Neve, L.: Immersion mode heterogeneous ice nucleation by an illite rich powder representative of atmospheric mineral dust, Atmos. Chem. Phys., 12, 287-307, doi:10.5194/acp-12-287-2012, 2012.

Bryant, G. W., Hallett, J., and Mason, B. J.: The epitaxial growth of ice on single-crystalline substrates, J. Phys. Chem. Solids, 12, 189-195, 1959.

Chen, J.-P. and Lamb, D.: The theoretical basis for the parameterization of ice crystal habits: Growth by vapor deposition, J. Atmos. Sci., 51, 9, 1206-1221, 1994.

Chen, J.-P., Hazra, A., and Levin, Z.: Parameterizing ice nucleation rates using contact angle and activation energy derived from laboratory data, Atmos. Chem. Phys., 8, 7431-7449, doi:10.5194/acp-8-7431-2008, 2008.

Christner, B. C., Morris, C. E., Foreman, C. M., Cai, R., and Sandis, D. C.: Ubiquity of biological ice nucleators in snowfall, Science, 319, 1214, doi:10.1126/science.1149757, 2008.

Connolly, P. J., Möhler, O., Field, P. R., Saathoff, H., Burgess, R., Choularton, T., and Gallagher, M.: Studies of heterogeneous freezing by three different desert dust samples, Atmos. Chem. Phys., 9, 2805-2824, doi:10.5194/acp-9-2805-2009, 2009.

Cotton, R. J. and Field, P. R.: Ice nucleation characteristics of an isolated wave cloud, Q. J. R. Meteor. Soc., 128, 2417-2437, 2002.

Cotton, W. R., Tripoli, G. J., Rauber, R. M., and Mulvihill, E. A.: Numerical Simulation of the Effects of Varying Ice Crystal Nucleation Rates and Aggregation Processes on Orographic Snowfall, J. Clim. Appl. Meteorol., 25, 11, 1658-1680, doi:10.1175/1520-0450(1986)025<1658:NSOTEO > 2.0.CO;2, 1986.

Crawford, I., Möhler, O., Schnaiter, M., Saathoff, H., Liu, D., McMeeking, G., Linke, C., Flynn, M., Bower, K. N., Connolly, P. J., Gallagher, M. W., and Coe, H.: Studies of propane flame soot acting as heterogeneous ice nuclei in conjunction with single particle soot photometer measurements, Atmos. Chem. Phys., 11, 9549-9561, doi:10.5194/acp-11-9549-2011, 2011.

Crawford, I., Bower, K. N., Choularton, T. W., Dearden, C., Crosier, J., Westbrook, C., Capes, G., Coe, H., Connolly, P. J., Dorsey, J. R., Gallagher, M. W., Williams, P., Trembath, J., Cui, Z., and Blyth, A.: Ice formation and development in aged, wintertime cumulus over the UK: observations and modelling, Atmos. Chem. Phys., 12, 4963-4985, doi:10.5194/acp-12-4963-2012, 2012.

Crosier, J., Bower, K. N., Choularton, T. W., Westbrook, C. D., Connolly, P. J., Cui, Z. Q., Crawford, I. P., Capes, G. L., Coe, H., Dorsey, J. R., Williams, P. I., Illingworth, A. J., Gallagher, M. W., and Blyth, A. M.: Observations of ice multiplication in a weakly convective cell embedded in supercooled mid-level stratus, Atmos. Chem. Phys., 11, 257-273, doi:10.5194/acp-11-257-2011, 2011.

Curry, J.: Interactions among aerosols, clouds, and climate of the Arctic Ocean, Sci. Tot. Environ., 160/161, 777-791, 1995.

Curry, J. A. and Khvorostyanov, V. I.: Assessment of some parameterizations of heterogeneous ice nucleation in cloud and climate models, Atmos. Chem. Phys., 12, 1151-1172, doi:10.5194/acp12-1151-2012, 2012.

de Boer, G., Hashino, T., and Tripoli, G. J.: Ice nucleation through immersion freezing in mixed-phase stratiform clouds: Theory and numerical simulations, Atmos. Res., 96, 315-324, 2010.
DeMott, P. J., Sassen, K., Poellot, M. R., Baumgardner, D., Rogers, D. C., Brooks, S. D., Prenni, A. J., and Kreidenweis, S. M.: African dust aerosols as atmospheric ice nuclei, Geophys. Res. Lett., 30, 1732, doi:10.1029/2003GL017410, 2003.

DeMott, P. J., Prenni, A. J., Liu, X., Kreidenweis, S. M., Petters, M. D., Twohy, C. H., Richardson, M. S., Eidhammer, T., and Rogers, D. C.: Predicting global atmospheric ice nuclei distributions and their impacts on climate, P. Natl. Acad. Sci., 107, 11217-11222, doi:10.1073/pnas.0910818107, 2010.

Diehl, K. and Wurzler, S.: Heterogeneous drop freezing in the immersion mode: Model calculations considering soluble and insoluble particles in the drops, J. Atmos. Sci., 61, 2063-2072, 2004.

Diehl, K., Matthias-Maser, S., Jaenicke, R., and Mitra, S. K.: The ice nucleating ability of pollen:: Part II. Laboratory studies in immersion and contact freezing modes, Atmos. Res., 61, 125133, doi:10.1016/s0169-8095(01)00132-6, 2002.

Eidhammer, T., DeMott, P. J., and Kreidenweis, S. M.: A comparison of heterogeneous ice nucleation parameterizations using a parcel model framework, J. Geophys. Res., 114, D06202, doi:10.1029/2008JD011095, 2009.

Ervens, B., Feingold, G., Sulia, K., and Harrington, J.: The impact of microphysical parameters, ice nucleation mode, and habit growth on the ice/liquid partitioning in mixedphase Arctic clouds, J. Geophys. Res., 116, D17,D17205, doi:10.1029/2011jd015729, 2011.

Field, P. R., Heymsfield, A. J., Shipway, B. J., DeMott, P. J., Pratt, K. A., Rogers, D. C., Stith, J., and Prather, K. A.: Ice in Clouds Experiment - Layer Clouds. Part 2: Testing characteristics of heterogeneous ice formation in lee wave clouds, J. Atmos. Sci., 69, 1066-1079, doi:10.1175/jas-d-11-026.1, 2011.

Fletcher, N. H.: Size effects in heterogeneous nucleation, J. Chem. Phys., 29, 572-576, 1958.

Fletcher, N. H.: Active sites and ice nucleation, J. Atmos. Sci., 26, 1266-1271, 1969.

Fridlind, A. M., Ackermann, A. S., McFarquhar, G., Zhang, G., Poellot, M. R., DeMott, P. J., Prenni, A. J., and Heymsfield, A. J.: Ice properties of single-layer stratocumulus clouds during the Mixed-Phase Arctic Cloud Experiment: 2. Model results, J. Geophys. Res., 112, D24202, doi:10.1029/2007JD008646, 2007.

Fukuta, N.: Experimental studies of organic ice nuclei, J. Atmos. Sci., 23, 191-196, 1966.

Fukuta, N. and Schaller, R. C.: Ice Nucleation by Aerosol Particles. Theory of Condensation-Freezing Nucleation, J. Atmos. Sci., 39, 648-655, doi:10.1175/15200469(1982)039<0648:inbapt >2.0.co;2, 1982.

Gorbunov, B., Baklanov, A., Kakutkina, N., Windsor, H. L., and Toumi, R.: Ice nucleation on soot particles, J. Aerosol Sci., 32, 199-215, doi:10.1016/s0021-8502(00)00077-x, 2001.

Hallett, J. and Mason, B. J.: The Influence of Temperature and Supersaturation on the Habit of Ice Crystals Grown from the Vapour, P. Roy. Soc. Lond. A Math., 247, 440-453, 1958.

Harrington, J. Y., Reisin, T., Cotton, W. R., and Kreidenweis, S. M.: Exploratory cloud resolving simulations of arctic stratus. Part II: Transition-season clouds, Atmos. Res., 51, 45-75, 1999.

Hobbs, P. V. and Rangno, A. L.: Ice Particle Concentrations in Clouds, J. Atmos. Sci., 42, 2523-2549, doi:10.1175/15200469(1985)042<2523:ipcic > 2.0.co;2, 1985.

Hoose, C., Kristjansson, J. E., Chen, J.-P., and Hazra, A.: A Classical-Theory-Based Parameterization of Heterogeneous Ice 
Nucleation by Mineral Dust, Soot, and Biological Particles in a Global Climate Model, J. Atmos. Sci., 67, 2483-2503, doi:10.1175/2010JAS3425.1, 2010.

Jeffery, C. A. and Austin, P. H.: Homogeneous nucleation of supercooled water: Results from a new equation of state, J. Geophys. Res., 102, 25269-25279, 1997.

Khvorostyanov, V. I. and Curry, J. A.: A new theory of heterogeneous ice nucleation for application on cloud and climate models, Geophys. Res. Lett., 27, 4081-4084, 2000.

Khvorostyanov, V. I. and Curry, J. A.: The theory of ice nucleation by heterogeneous freezing of deliquescent mixed CCN: Part I: Critical radius, energy, and nucleation rate, J. Atmos. Sci., 61, 2676-2691, 2004.

Khvorostyanov, V. I. and Curry, J. A.: The theory of ice nucleation by heterogeneous freezing of deliquescent mixed CCN: Part II: Parcel model studies, J. Atmos. Sci., 62, 261-285, 2005.

Korolev, A. and Isaac, G.: Phase transformation in mixed phase clouds, Q. J. Roy. Meteor. Soc., 129, 19-38, 2003.

Kulkarni, G. and Dobbie, S.: Ice nucleation properties of mineral dust particles: determination of onset $\mathrm{RH}_{i}$, IN active fraction, nucleation time-lag, and the effect of active sites on contact angles, Atmos. Chem. Phys., 10, 95-105, doi:10.5194/acp-10-95-2010, 2010.

Kulkarni, G., Fan, J., Comstock, J. M., Liu, X., and Ovchinnikov, M.: Laboratory measurements and model sensitivity studies of dust deposition ice nucleation, Atmos. Chem. Phys. Discuss., 12, 2483-2516, doi:10.5194/acpd-12-2483-2012, 2012.

Kumai, M.: Electron microscope study of snow-crystal nuclei, J. Meteorol., 8, 151-156, doi:10.1175/15200469(1951)008<0151:emsosc > 2.0.co;2, 1951.

Lamb, D. and Verlinde, H.: Physics and Chemistry of Clouds, 1st Edn., University Press, Cambridge, 584 pp., 2011.

Lance, S., Shupe, M. D., Feingold, G., Brock, C. A., Cozic, J., Holloway, J. S., Moore, R. H., Nenes, A., Schwarz, J. P., Spackman, J. R., Froyd, K. D., Murphy, D. M., Brioude, J., Cooper, O. R., Stohl, A., and Burkhart, J. F.: Cloud condensation nuclei as a modulator of ice processes in Arctic mixed-phase clouds, Atmos. Chem. Phys., 11, 8003-8015, doi:10.5194/acp-11-80032011, 2011.

Langham, E. J. and Mason, B. J.: The Heterogeneous and Homogeneous Nucleation of Supercooled Water, P. Roy. Soc. Lond. A Math., 247, 493-504, 1958.

Lüönd, F., Stetzer, O., Welti, A., and Lohmann, U.: Experimental study on the ice nucleation ability of size-selected kaolinite particles in the immersion mode, J. Geophys. Res., 115, D14201, doi:10.1029/2009jd012959, 2010.

Marcolli, C., Gedamke, S., Peter, T., and Zobrist, B.: Efficiency of immersion mode ice nucleation on surrogates of mineral dust, Atmos. Chem. Phys., 7, 5081-5091, doi:10.5194/acp-7-50812007, 2007.

Mason, B. J.: The growth of ice crystals in a supercooled water cloud, Q. J. Roy. Meteorol. Soc., 79, 441-441, doi:10.1002/qj.49707934121, 1953.

McDonald, J. E.: Use of the electrostatic analogy in studies of ice crystal growth, Z. Angew. Math. Phys., 14, 610-619, 1963.

McFarquhar, G., Zhang, G., Poellot, M. R., Kok, G. L., McCoy, R., Tooman, T., Fridlind, A. M., and Heymsfield, A. J.: Ice properties of single-layer stratocumulus clouds during the MixedPhase Arctic Cloud Experiment: 1. Observations, J. Geophys.
Res., 112, D24202, doi:10.1029/2007JD008633, 2007.

Meyers, M., DeMott, P. J., and Cotton, W. R.: New primary icenucleation parameterizations in an explicit cloud model, J. Appl. Meteorol., 31, 708-720, 1992.

Möhler, O., Field, P. R., Connolly, P., Benz, S., Saathoff, H., Schnaiter, M., Wagner, R., Cotton, R., Krämer, M., Mangold, A., and Heymsfield, A. J.: Efficiency of the deposition mode ice nucleation on mineral dust particles, Atmos. Chem. Phys., 6, 30073021, doi:10.5194/acp-6-3007-2006, 2006.

Morrison, H., Shupe, M. D., Pinto, J. O., and Curry, J. A.: Possible roles of ice nucelation mode and ice nuclei depletion in the extended lifetime of Arctic mixed-phase clouds, Geophys. Res. Lett., 32, L18801, doi:10.1029/2005GL023614, 2005.

Morrison, H., Pinto, J. O., Curry, J. A., and McFarquhar, G. M.: Sensitivity of modeled Arctic mixed-phase stratocumulus to cloud condensation and ice nuclei over regionally varying surface conditions, J. Geophys. Res., 113, D05203, doi:10.1029/2007JD008729, 2008.

Morrison, H., de Boer, G., Feingold, G., Harrington, J., Shupe, M. D., and Sulia, K.: Resilience of persistent Arctic mixed-phase clouds, Nat. Geosci., 5, 11-17, 2012.

Murray, B. J., Wilson, T. W., Dobbie, S., Cui, Z., Al-Jumur, S. M. R. K., Mohler, O., Schnaiter, M., Wagner, R., Benz, S., Niemand, M., Saathoff, H., Ebert, V., Wagner, S., and Karcher, B.: Heterogeneous nucleation of ice particles on glassy aerosols under cirrus conditions, Nat. Geosci., 3, 233-237, 2010.

Murray, B. J., Broadley, S. L., Wilson, T. W., Atkinson, J. D., and Wills, R. H.: Heterogeneous freezing of water droplets containing kaolinite particles, Atmos. Chem. Phys., 11, 4191-4207, doi:10.5194/acp-11-4191-2011, 2011.

Niedermeier, D., Hartmann, S., Shaw, R. A., Covert, D., Mentel, T. F., Schneider, J., Poulain, L., Reitz, P., Spindler, C., Clauss, T., Kiselev, A., Hallbauer, E., Wex, H., Mildenberger, K., and Stratmann, F.: Heterogeneous freezing of droplets with immersed mineral dust particles - measurements and parameterization, Atmos. Chem. Phys., 10, 3601-3614, doi:10.5194/acp-10-36012010, 2010.

Niedermeier, D., Shaw, R. A., Hartmann, S., Wex, H., Clauss, T., Voigtländer, J., and Stratmann, F.: Heterogeneous ice nucleation: exploring the transition from stochastic to singular freezing behavior, Atmos. Chem. Phys., 11, 8767-8775, doi:10.5194/acp11-8767-2011, 2011.

Niemand, M., Möhler, O., Vogel, B., Vogel, H., Hoose, C., Connolly, P., Klein, H., Bingemer, H., DeMott, P., Skrotzki, J., and Leisner, T.: A particle-surface-area-based parameterization of immersion freezing on desert dust particles, J. Atmos. Sci., doi:10.1175/jas-d-11-0249.1, in press, 2012.

Penner, J. E., Chen, Y., Wang, M., and Liu, X.: Possible influence of anthropogenic aerosols on cirrus clouds and anthropogenic forcing, Atmos. Chem. Phys., 9, 879-896, doi:10.5194/acp-9-8792009, 2009.

Phillips, V. T. J., DeMott, P. J., and Andronache, C.: An empirical parameterization of heterogeneous ice nucleation for multiple chemical species of aerosol, J. Atmos. Sci., 65, 2757-2783, 2008.

Pinti, V., Marcolli, C., Zobrist, B., Hoyle, C. R., and Peter, T.: Ice nucleation efficiency of clay minerals in the immersion mode, Atmos. Chem. Phys. Discuss., 12, 3213-3261, doi:10.5194/acpd-12-3213-2012, 2012. 
Popovicheva, O., Kireeva, E., Persiantseva, N., Khokhlova, T., Shonija, N., Tishkova, V., and Demirdjian, B.: Effect of soot on immersion freezing of water and possible atmospheric implications, Atmos. Res., 90, 326-337, doi:10.1016/j.atmosres.2008.08.004, 2008.

Roberts, P. and Hallett, J.: A laboratory study of the ice nucleating properties of some mineral particulates, Q. J. Roy. Meteor. Soc., 94, 25-34, doi:10.1002/qj.49709439904, 1968.

Schnell, R. C. and Vali, G.: Biogenic ice nuclei: Part I. Terrestrial and marine sources, J. Atmos. Sci., 33, 1554-1564, 1976.

Shaw, R. A., Durant, A. J., and Mi, Y.: Heterogeneous Surface Crystallization Observed in Undercooled Water, J. Phys. Chem. B, 109, 9865-9868, doi:10.1021/jp0506336, 2005.

Solomon, S., Qin, D., Manning, M., Chen, Z., Marquis, M., Averyt, K. B., Tignor, M., and Miller, H. L.: Climate Change 2007 - The Physical Science Basis, Contribution of Working Group I to the Fourth Assessment Report of the IPCC, Intergovernmental Panel on Climate Change, Cambridge, United Kingdom and New York, NY, USA, 2007.

Sulia, K. J. and Harrington, J. Y.: Ice aspect ratio influences on mixed-phase clouds: Impacts on phase partitioning in parcel models, J. Geophys. Res., 116, D21309, doi:10.1029/2011jd016298, 2011.

Takahashi, T., Endoh, T., Wakahama, G., and Fukuta, N.: Vapor diffusional growth of freefalling snow crystals between -3 and $-23^{\circ}$ C, J. Meteorol. Soc. Jpn., 69, 15-30, 1991.

Vali, G.: Quantitative Evaluation of Experimental Results an the Heterogeneous Freezing Nucleation of Supercooled Liquids, J. Atmos. Sci., 28, 402-409, doi:10.1175/15200469(1971)028<0402:QEOERA > 2.0.CO;2, 1971.
Vali, G.: Freezing rate due to heterogeneous nucleation, J. Atmos. Sci., 51, 1843-1856, 1994.

Vali, G.: Repeatability and randomness in heterogeneous freezing nucleation, Atmos. Chem. Phys., 8, 5017-5031, doi:10.5194/acp-8-5017-2008, 2008.

Vali, G. and Stansbury, E. J.: Time-dependent characteristics of the heterogenous nucleation of ice, Can. J. Phys., 44, 477-502, 1966.

Vonnegut, B. and Baldwin, M.: Repeated Nucleation of a Supercooled Water Sample that Contains Silver Iodide Particles, J. Clim. Appl. Meteorol., 23, 486-490, doi:10.1175/15200450(1984)023<0486:rnoasw>2.0.co;2, 1984.

Wang, B. and Knopf, D. A.: Heterogeneous ice nucleation on particles composed of humic-like substances impacted by $\mathrm{O}_{3}$, J. Geophys. Res., 116, D03205, doi:10.1029/2010jd014964, 2011.

Welti, A., Lüönd, F., Stetzer, O., and Lohmann, U.: Influence of particle size on the ice nucleating ability of mineral dusts, Atmos. Chem. Phys., 9, 6705-6715, doi:10.5194/acp-9-6705-2009, 2009.

Welti, A., Lüönd, F., Kanji, Z. A., Stetzer, O., and Lohmann, U.: Time dependence of immersion freezing, Atmos. Chem. Phys. Discuss., 12, 12623-12662, doi:10.5194/acpd-12-12623-2012, 2012.

Wheeler, M. J. and Bertram, A. K.: Deposition nucleation on mineral dust particles: a case against classical nucleation theory with the assumption of a single contact angle, Atmos. Chem. Phys., 12, 1189-1201, doi:10.5194/acp-12-1189-2012, 2012.

Zobrist, B., Koop, T., Luo, B. P., Marcolli, C., and Peter, T.: Heterogeneous Ice Nucleation Rate Coefficient of Water Droplets Coated by a Nonadecanol Monolayer, J. Phys. Chem. C, 111, 2149-2155, 2007. 